\title{
La mezquita del fortín emiral del Tossal de la Vila (Castellón). Secuencia estratigráfica y diseño arquitectónico de un edificio religioso rural en los albores del islam andalusí
}

\author{
The mosque in the emiral fortress of Tossal de la Vila (Castellón). Stratigraphic \\ sequence and architectural design of a religious edifice in the dawn of Andalusi \\ Islam
}

\begin{abstract}
Joan Negre Pérez, Universitat Autònoma de Barcelona, España, Museu Arqueològic de Gandia, España, joan.negre@gandia.org, https://orcid.org/0000-0002-2804-1467

Ferran Falomir Granell, Servei d’Investigacions Arqueològiques i Prehistòriques, Diputació de Castelló, España, ffalomir@dipcas. es, https://orcid.org/0000-0001-9796-5834

Marta Pérez-Polo, Universidad de Navarra, España, marta.perez.polo@gmail.com, https://orcid.org/0000-0002-3359-7726

Gustau Aguilella Arzo, Servei d’Investigacions Arqueològiques i Prehistòriques, Diputació de Castelló, España, gustauaguilella@ dipcas.es, https://orcid.org/0000-0002-5197-8274
\end{abstract}

\section{Resumen}

Este trabajo presenta los recientes resultados procedentes de la excavación en extensión del sector 14 del yacimiento arqueológico del Tossal de la Vila (Serra d'en Galceran, Castellón), durante la cual se ha recuperado un edificio que identificamos como la mezquita comunitaria adscrita a este recinto fortificado de época emiral. Se trata de un oratorio rural situado dentro de una fortificación que no cuenta con un área de poblamiento estable anexa a ella, y que presenta una secuencia de ocupación que abarca, según los múltiples análisis radiocarbónicos realizados, desde finales del siglo VIII hasta la primera mitad del siglo X. Diversos factores que consideramos coincidentes con nuestra propuesta, como la orientación del edificio, su morfología y distribución espacial, la técnica constructiva claramente diferenciada de la del resto de construcciones del fortín o sus paralelismos con otros oratorios conocidos, son indicios de entidad para considerar a sus ocupantes como un grupo tempranamente islamizado, cuya identidad u obediencia nos es aún esquiva. Los ejemplos de edificios de esta tipología en cronologías andalusíes tempranas resultan además considerablemente difíciles de encontrar, más aún en contextos rurales y extremadamente periféricos como el que nos ocupa. Es por ello que este caso de estudio resulta de gran interés, tanto por la información que aporta al debate específico sobre los recintos fortificados emirales en el Šarq al-Andalus como, sobretodo, por los múltiples ángulos y perspectivas que abre en relación al análisis de las primeras mezquitas rurales de

\begin{abstract}
This work presents the results from the excavation of sector 14 within the archaeological site of Tossal de la Vila (Serrà d'en Galceran, Castellón), where a construction was identified as the communal mosque of this fortified site, dating from the early al-Andalus period. A rural place of worship inside a military enclosure without a nearby permanent settlement area, occupied -according to several radiocarbon datings performed throughout our project- between the last decades of $8^{\text {th }}$ century and the first half of the $10^{\text {th }}$. Several factors in line with our proposal, such as the orientation of the building, its morphology and spatial distribution, the construction technique -clearly different from the rest of constructions in the fortress- or the similarity with other known rural mosques, are clear enough evidence for considering their inhabitants to be an early Islamised group, whose identity or obedience still remain blurry. There are very few examples of this kind of building in early al-Andalus chronologies, even more so in rural and peripheral contexts, such as this one. Therefore, this is an engaging case study due to the information related to the debate on fortified hillforts in Šarq al-Andalus, but especially to the fact that it gives new points of view regarding the first rural mosques and the Islamization process that they represent. From a global point of view, it is important to understand that these Islamic rural mosques, such as our case study or the one located at the Molón archaeological site (Camporrobles, Valencia), share a series of features that we attempt to systematize in this study.
\end{abstract}

Financiación: Trabajo integrado dentro del proyecto «Entre al-Andalus y la feudalidad. Poderes territoriales y desarrollo de sistemas defensivos altomedievales en el nordeste peninsular» (PID2020-114484GB-I00), Ministerio de Ciencia e Innovación. 
al-Andalus y del proceso de islamización del cual son su reflejo material. Desde un punto de visto global, resulta también de gran importancia empezar a poner en relación estos primeros edificios religiosos rurales, como nuestro caso de estudio o el identificado en la fortaleza del Molón (Camporrobles, Valencia), con una serie de características que parecen ser comunes entre ellos y que en este artículo tratamos de sistematizar.

Palabras clave. Mezquita; Šarq al-Andalus; emiral; islamización; fortificación.
Key words. Mosque; Šarq al-Andalus; emiral; Islamization; fortification.

\section{INTRODUCCIÓN}

La identificación y estudio de pequeñas mezquitas en el ámbito rural ha sido considerada, desde los primeros trabajos vinculados a la secuenciación del proceso de islamización en al-Andalus, un elemento central en el debate historiográfico. La posibilidad de comparar, a través suyo, las características de la arquitectura sacra en contextos urbanos y aquella desarrollada en su periferia aporta información crucial a nivel social, cultural, económico y político, que excede con creces el análisis de la difusión del islam como religión. Además, la posibilidad de reunir un conjunto cada vez más numeroso de casos de estudio en el contexto específico del Šarq al-Andalus permitirá, a medio plazo, el análisis diacrónico comparado entre regiones, tanto peninsulares como norteafricanas, con el objetivo de plantear posibles ritmos desiguales entre territorios de un Dār al-Islām en vías de vertebración.

En el caso específico que nos ocupa, la posible mezquita identificada en el yacimiento arqueológico del Tossal de la Vila apunta hacia unos modelos constructivos, técnicas de alzado y organización del espacio, que resultan prácticamente inéditos en el ámbito andalusí. Analizaremos, por lo tanto, los principales elementos que nos llevan a proponer su adscripción como mezquita, así como los diferentes indicadores que la excavación de este yacimiento nos ha proporcionado en cuanto al estudio del grado de islamización de sus ocupantes. El objetivo, finalmente, es el de integrar este ejemplo específico con el resto de mezquitas rurales documentadas en el ámbito geográfico del Šarq alAndalus, al mismo tiempo que tratamos de identificar las semejanzas y discrepancias entre ellas en función de su momento fundacional y el contexto militar, religioso o civil en el que aparecieron.

En conjunto, nuestra problemática de estudio se integra dentro de un debate aún más amplio en torno al reconocimiento de los primeros asentamientos andalusíes en este sector de al-Andalus, y que tiene en la figura de André Bazzana su punto de origen. Fue él quien identificó, en las comarcas castellonenses, una serie de asentamientos en altura con evidencias de un incipiente urbanismo y con un amplio registro arqueológico de origen local, para los cuales intuía funciones de vigilancia viaria y refugio de las poblaciones campesinas cercanas (Bazzana, 1992: 273-275). De la misma manera, también propuso la construcción coetánea de otro tipo de recintos, descritos en sus textos como enigmáticos y que, a pesar de presentar evidentes coincidencias con los primeros, no disponían de estructuras o contextos materiales suficientes para ser identificados como algo más que simples rediles o espacios para la actividad ganadera (Bazzana, 1992: 348-353). Así, es también nuestro objetivo situar progresivamente el yacimiento arqueológico del Tossal de la Vila dentro de esta discusión historiográfica, iniciada en los años setenta por la escuela francesa y recientemente retomada a través de un minucioso trabajo de campo y la revisión completa de todas las fuentes escritas y arqueológicas (Negre, 2020: 223-227).

\section{EL YACIMIENTO EN CONTEXTO}

El Tossal de la Vila (Serra d'en Galceran, Castellón) se sitúa en una de las cimas más preeminentes al sur de la sierra d'En Galceran, a 954 m de altura, abarcando una amplia plataforma rocosa cercana a los $5000 \mathrm{~m}^{2}$ de extensión, con verticales inaccesibles por su lado este pero con accesos más suaves desde el resto de direcciones. La cadena montañosa donde se sitúa el sitio arqueológico presenta una orientación catalánide, delimitada al sureste por el corredor de Les Coves -a través del cual discurría la antigua Vía Augusta- y al noroeste por la rambla Carbonera-que circunscribe el paso andalusí desde la costa hacia Alcañiz- (Fig. 1). Se trata, por tanto, de un enclave estratégico de control viario en la bifurcación de los caminos que, desde la ciudad de Valencia, se dirigían hacia Tortosa y Zaragoza (Negre, 2020: 119-133).

En el yacimiento del Tossal de la Vila se han ejecutado hasta la actualidad diez campañas de excavación (2012-2020), impulsadas desde el Servei d'Investigacions Arqueològiques i Prehistòriques de la Diputació de Castelló (SIAP). A lo largo de estas intervenciones se han podido documentar hasta seis fases de ocupación diferenciadas en dos grandes períodos. Así, las fases 0 , I y II se extienden desde inicios del siglo VIII hasta la primera mitad del VII a. n. e. y están vinculadas a un asentamiento fortificado con estructuras domésticas, cuyo registro material abarca desde la Edad del Bronce Final hasta las primeras relaciones coloniales mediterráneas, enmarcadas en el Hierro Antiguo (Aguilella et al., 2016). Mientras tanto, las fases III y IV corresponden a un recinto amurallado de época emiral 


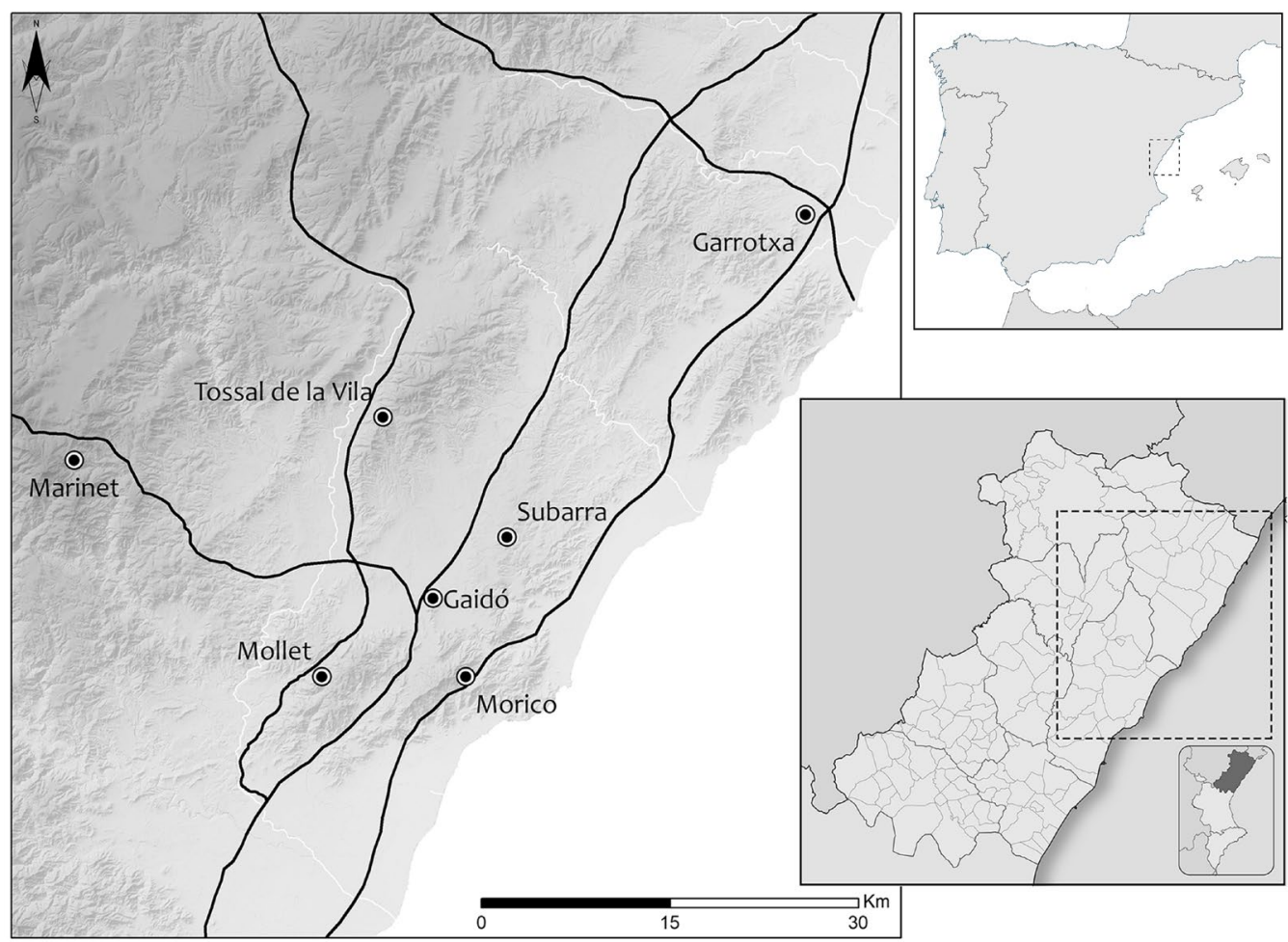

Figura 1: Localización del Tossal de la Vila, junto a los principales yacimientos arqueológicos y vías de comunicación mencionados en el texto

que, según el estado actual de conocimientos, mostraría una ocupación más o menos estable entre finales del siglo VIII e inicios del X (Negre et al., 2020a).

De esta manera, el ámbito geográfico y cronológico durante el cual se habría edificado la fortificación altomedieval, así como también otros casos cercanos y con abundantes puntos en común como Mollet (Sant Joan de Moró) o Marinet (Xodos), se presenta plagado de episodios relevantes y bien documentados que podrían haber influido en su construcción. Son buena prueba de ello las distintas revueltas bereberes de la segunda mitad del siglo VIII en los territorios de Santaver o la instalación de 'Abd Allāh al-Balansī en los dominios de Valencia durante el primer cuarto de la siguiente centuria. En este sentido, es necesario destacar que la localización de todos estos emplazamientos en altura coincide con el espacio en el cual se fijaría el límite entre Tortosa y Valencia a partir del siglo IX, delimitado por los últimos contrafuertes del sistema Ibérico desde el macizo del Penyagolosa y las sierras litorales de Borriol y Les Palmes, hecho que podría tener importantes implicaciones históricas (Negre, 2020: 404-405).

También resulta de interés, a la hora de fijar el contexto histórico durante el que se construyeron estas fortificaciones, situadas en los límites entre los territorios de estas dos importantes ciudades emirales, la carta que el gobernador de la primera, 'Ubayd Allāh b. Yahyyà, envió en el año 850-851 al emir 'Abd al-Raḥmān b. al-Hakam, en la cual daba cuenta de la situación de sus dominios. Entre otras informaciones, el gobernador de Tortosa afirmaba que con las recaudaciones que llegaban al erario público a través de sus agentes fiscales, disponía de suficientes recursos para hacer frente a la reparación de sus fortalezas (hușūn) y que, por tanto, enviaba el escuadrón de caballería que el emir le había destinado a ocupar los apriscos situados sobre la costa (marābiti-him bi-l-mä). Como veremos, nuestro yacimiento responde probablemente a la primera de estas realidades, como Mollet o Marinet, atendiendo a las importantes estructuras de asentamiento aparecidas en todos ellos. En contraposición, los marābit pueden vincularse sin excesivos problemas con clausuras como las identificadas en Gaidó (Cabanes), Subarra (Benlloc) o Garrotxa (Peníscola), los recintos enigmáticos de Bazzana. Se trata, estos últimos, de espacios de grandes dimensiones cercados mediante muros de mampostería en seco idénticos a los de las fortalezas principales, en los cuales no se observan ámbitos de asentamiento permanente y para los cuales proponemos su uso como lugar de instalación para guarniciones móviles destinadas a la vigilancia costera y vial (Negre y Suñé, 2019; Negre, 2020: 223-227).

En lo que respecta a la descripción general del yacimiento, el recinto fortificado del Tossal de la Vila está perfectamente delimitado por un acantilado, que bordea todo el perímetro oriental y septentrional del yacimiento, y una potente muralla, jalonada mediante torres y bastiones, que protege principalmente el lado oeste y sur, los cuales resultan más fácilmente accesibles (Fig. 2). La defensa perimetral de la fortificación está levantada mediante dos paramentos con basamento de 


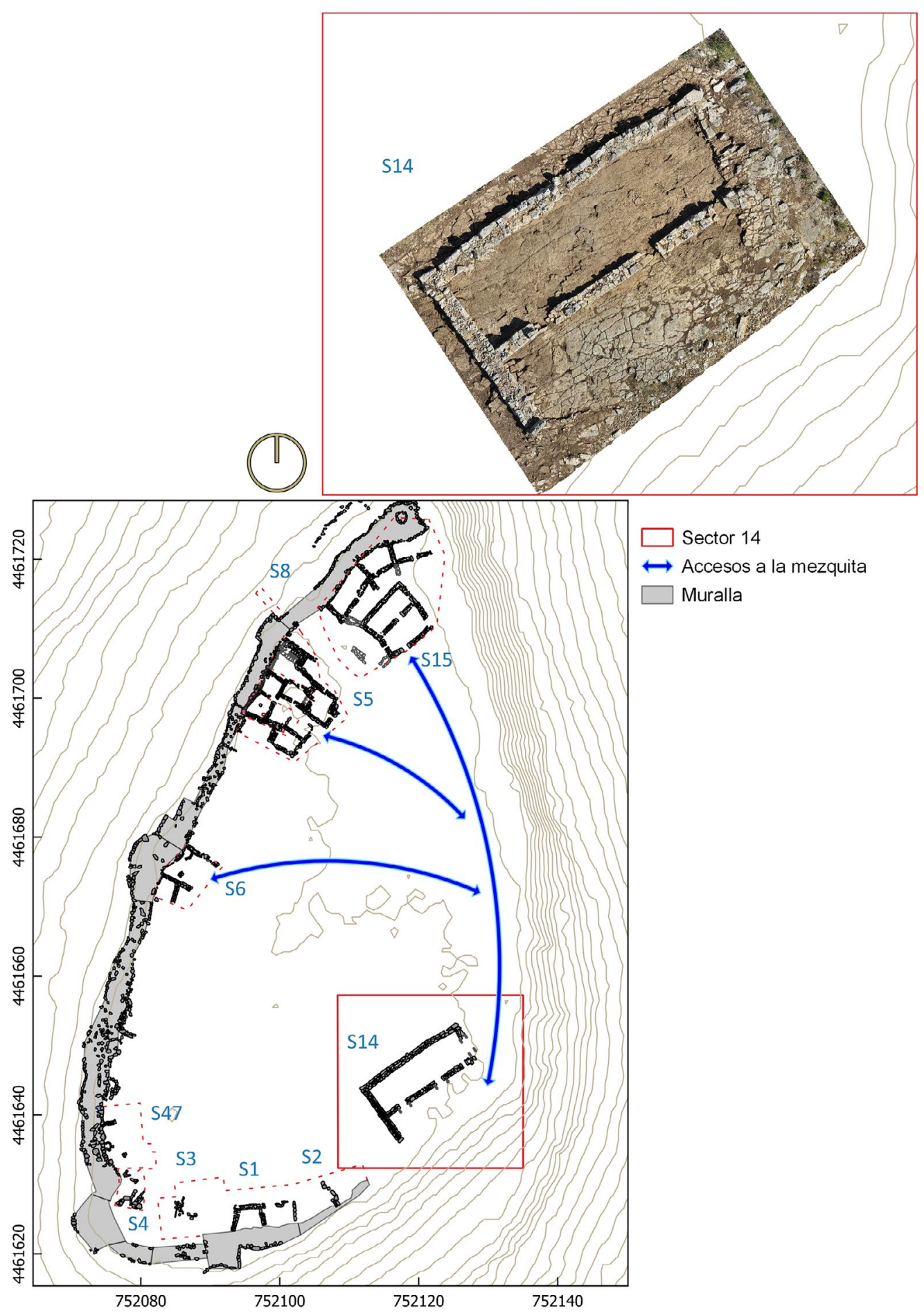

Figura 2: Planta general del yacimiento, accesos a la mezquita y ortofotografía del sector 14

grandes bloques unidos mediante mampostería en seco, de más de tres metros de anchura media, con un relleno interno de bloques y gravas de menores dimensiones. En los lugares en los cuales la pendiente del altiplano resulta demasiado pronunciada para la construcción, el desnivel topográfico se ve solucionado mediante un aterrazamiento formado por bloques ciclópeos y una unidad de gravas con tierra sobre la que se asentó la muralla. Ésta se vio, además, reforzada mediante dos torres de planta cuadrangular y diversos bastiones de menor entidad, con claras evidencias de reformas sobre la poliorcética que están en vías de estudio (Negre et al., 2020b: 157-158).

Actualmente, a partir de las dataciones absolutas obtenidas y su relación con la secuencia estratigráfica y el registro arqueológico del yacimiento, se puede proponer con cierta seguridad una primera fase constructiva de este recinto, vinculada al levantamiento de esta muralla y a los primeros indicios de urbanismo, entre el último cuarto del siglo VIII o inicios de la siguiente 
centuria ${ }^{1}$. Las diferentes construcciones interiores de este primer momento, relacionadas con módulos simples adosados a la muralla y al menos dos edificios exentos de carácter monumental, uno de ellos identificado como una mezquita y el otro como un espacio residencial privilegiado, constituyen un buen ejemplo de los modelos arquitectónicos defensivos propios de esta zona del Šarq al-Andalus durante el emirato. Junto con otros indicios, la posterior evolución de algunos de los módulos simples hacia viviendas más complejas compuestas por varios módulos dispuestos en torno a un patio, con pocos indicios de ortogonalidad respecto a las edificaciones anteriores, parecen indicar un proceso de desarrollo constructivo entrecortado y poco planificado, reflejo de una alternancia entre ocupación y abandono o refacción hasta las décadas iniciales del siglo $\mathrm{X}^{2}$

Además, el estudio de los diferentes registros arqueológicos recuperados durante las excavaciones ha permitido profundizar sobre la modalidad de asentamiento que se produciría en este recinto, conduciéndonos a proponer el establecimiento de grupos militarizados de duración desconocida. Un colectivo, el de sus ocupantes, que aún no hemos podido identificar, por lo que resulta difícil asociar esta dinámica a una iniciativa estatal, a través de los gobernadores de Tortosa o Valencia, o a los intentos de algún grupo local por establecer allí un cierto poder autónomo. Sea cual fuere su patrocinador, lo cierto es que la presencia allí de una mezquita, el consumo prácticamente anecdótico de suidos o el desarrollo doméstico de una unidad modular compleja estructurada progresivamente en torno a un patio (vid. Gutiérrez Lloret, 2012: 147-148), son indicios de entidad para considerar a sus ocupantes como un grupo tempranamente islamizado, más aún si tomamos en consideración lo periférico y marginal de nuestro caso de estudio (Negre et al., 2020a).

1. Muestra Beta-503127/TV17-5089 (material carbonizado); hogar vinculado estratigráficamente al momento de uso de la cocina comunitaria, posterior a la primera fase constructiva; edad radiocarbónica convencional 791-851, edad

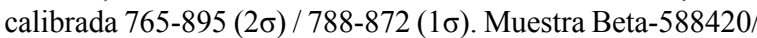
TV18-5117 (material carbonizado); hogar vinculado estratigráficamente al momento de amortización de uno de los primeros módulos anexos a la muralla; edad radiocarbónica

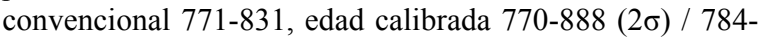
$835(1 \sigma)$

2. Muestra Beta-419185/TV15-5017 (material carbonizado); hogar sellado por una losa, vinculado estratigráficamente al momento de abandono definitivo del recinto; edad radiocar-

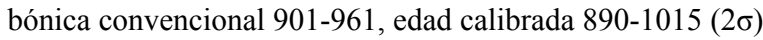

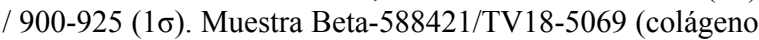
óseo); depósito de fauna vinculado al momento de amortización de diversos de los espacios iniciales construidos; edad radiocarbónica convencional 861-921, edad calibrada 875-994 $(2 \sigma) / 915-976(1 \sigma)$.

\section{LA MEZQUITA DEL TOSSAL DE LA VILA}

En el sector sureste del yacimiento se detectaron, ya durante las primeras excavaciones en el interior del recinto, indicios de la existencia de un gran edificio, que en planta parecía disponer de dos naves dispuestas longitudinalmente. Su situación espacial aislada dentro del hábitat (Fig. 2), con una significativa orientación general hacia el SSE, así como la nula relación con el resto de construcciones circundantes, la monumentalidad de los paramentos emergentes o su aparente ejecución constructiva unitaria, nos llevó a plantear la posibilidad de podernos encontrar ante una mezquita rural comunitaria de cierta entidad. Durante los años 2018-2020 se procedió a la excavación sistemática y en extensión de este edificio con el objetivo de contrastar la hipótesis planteada; una intervención que permitió documentar una serie de características que seguidamente pasamos a detallar.

\subsection{ORIENTACIÓN}

Ciertamente, uno de los elementos a los cuales suele atenderse en primera instancia a la hora de identificar una mezquita, es su orientación. Considerar la prescripción coránica de direccionar correctamente los rezos, sacrificios, enterramientos o tantas otras actividades diarias es una de las obligaciones primordiales de la comunidad musulmana y, por ello, ha dado lugar a una extensa producción literaria jurídico-religiosa. Los protagonistas principales de esta discusión fueron tanto astrónomos como alfaquíes; los primeros por sus conocimientos de orientación y posicionamiento - por lo general limitados por la dificultad para establecer la ubicación geográfica de cada mezquita-, y los segundos por el carácter jurisprudente de sus deliberaciones, que legitimaban o denunciaban los cálculos astronómicos. Por lo general, la decisión final sobre dónde construir la alquibla (del ár. al-qibla, 'la Dirección' en el sentido estricto de la dirección hacia la Meca) de una mezquita correspondía a una especie de común acuerdo entre el mundo del conocimiento científico, encarnado en la figura de los astrónomos, y el del juicio teológico, ejercido por los alfaquíes. En otras ocasiones, sin embargo, una de las dos opciones se imponía sobre la otra. A pesar de ello, no existe una única alquibla o dirección aceptada, sino que los métodos y las orientaciones varían según el momento y los condicionantes sociales, jurídicos y religiosos imperantes.

En el caso de al-Andalus, y más concretamente durante el período emiral, los conocimientos de trigonometría eran aún muy escasos, por lo que los métodos que tuvieron una mayor difusión y uso a la hora de implementar una correcta o aceptable orientación de las mezquitas fueron los de la llamada astronomía popular. Esto es, aquellos conocimientos sobre la posición de los astros, principalmente el Sol, y su posición conocida durante los solsticios y equinoccios, que variaba 


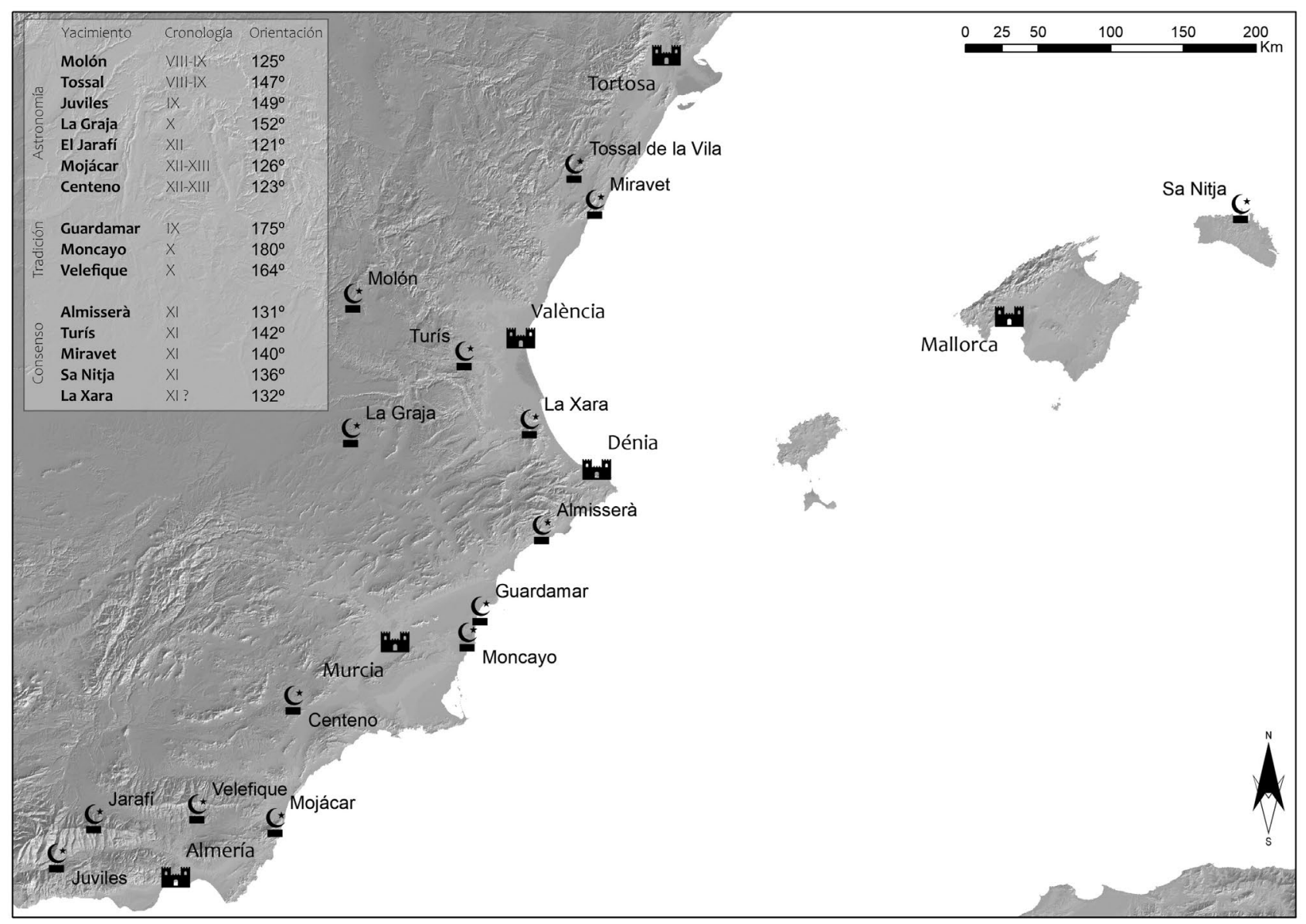

Figura 3: Localización de las mezquitas rurales y principales núcleos urbanos del Šarq al-Andalus mencionados en el texto

ligeramente en función de las coordenadas en la que el observador se encontraba. Esta situación llevó a la convivencia, dentro de la Península, entre diferentes prácticas en cuanto a la orientación de las mezquitas, siempre enmarcadas dentro del cuadrante general SE, en el que se encuentra la dirección real hacia La Meca $\left(100^{\circ}-105^{\circ}\right)$, y tomando en consideración posibles factores locales, como la orografía, la trama urbana previa (de existir) o la reutilización de edificios anteriores.

Los detallados estudios realizados por Alfonso Jiménez, Mònica Rius o David A. King, en relación a la orientación de las mezquitas de al-Andalus, han permitido discernir diferentes tendencias según los métodos y dirección escogidos. En primer lugar, podemos agrupar aquellos templos que, por su preeminencia y disponibilidad de espacio, contaron con cálculos trigonométricos y astronómicos más precisos $\left(101^{\circ}-109^{\circ}\right)$. Seguidamente, las que, de forma genérica, situaron su alquibla hacia el orto del Sol durante el solsticio de invierno $\left(115^{\circ}-125^{\circ}\right)$. Otro grupo lo conforman aquellas que adoptaron una solución de compromiso entre los partidarios de una dirección general $\mathrm{E}$ y los que priorizaban el $\mathrm{S}$, los cuales orientaron la alquibla de forma general hacia el SE $\left(130^{\circ}-142^{\circ}\right)$. Desde otra perspectiva, destacan las mezquitas que, a imitación de la aljama cordobesa, tomaron la orientación de la $\mathrm{Ka}$ 'ba, es decir, hacia el orto de la estrella Suhayl, que en al-Andalus se encuentra entre los $146^{\circ}-150^{\circ}$. Esto es, establecieron su alquibla de forma paralela al muro NO del sagrado edificio mequí (King, 2018: 204), a pesar de no existir documento alguno que explicite esta práctica (King, 2018: 211). Al no poder observarse este astro desde nuestras latitudes, el método usado por la astronomía popular fue el de orientar el lado menor de la mezquita hacia el orto solar durante el solsticio de verano (en al-Andalus, entre $56^{\circ}$ y $60^{\circ}$ ), quedando la alquibla ortogonal respecto a éste. Finalmente, la última tendencia agrupa las mezquitas de orientación meridional, ubicadas en un amplio rango entre $165^{\circ}-195^{\circ}$, fruto de dinámicas arraigadas a la tradición, con amplia aceptación en la taifa de Toledo y la Sevilla almohade (Jiménez, 1991; Rius, 2000: 104-121).

Para el análisis específico del ámbito general del Šarq al-Andalus, el espacio geográfico (Fig. 3) en el cual se integra nuestro caso de estudio, son pocas las mezquitas que se conocen, que además pertenecen a yacimientos de cronologías muy diversas, por lo que resulta complicado discernir entre tendencias. El ejemplo más antiguo de los documentados, con un marco temporal muy similar al de la mezquita del Tossal de la Vila, es el templo de la fortaleza del Molón (Lorrio y Sánchez de Prado, 2008), en Camporrobles (Valencia), orientada a $125^{\circ}$, lo que parece coincidir con las alquiblas establecidas a partir del orto solar en el solsticio 
de invierno, que en el enclave exacto del yacimiento se encuentra aproximadamente a $120^{\circ}$. Aunque no disponemos de una cronología precisa para su construcción, en la fortaleza de Juviles (Granada), cuyo papel durante las revueltas finales del emirato es ampliamente referenciado por las fuentes escritas, se ha podido excavar también una mezquita de dimensiones considerables y orientada a $149^{\circ}$, es decir, usando la posición del Sol durante su zenit estival (Rouco, 2021: 474-476).

Siguiendo el orden diacrónico, el conjunto arquitectónico del ribāt de Guardamar (Alacant) es otro de los ejemplos mejor documentados en cronología temprana, desarrollado en términos generales entre los siglos IX y XI (Azuar, 2004; Azuar (Ed.), 2004), aunque la orientación varía de forma amplia dentro de los distintos oratorios y la mezquita, en una horquilla entre los $144^{\circ}$ y los $185^{\circ}$. Interpretamos, pues, que se debió optar por una orientación general hacia el $\mathrm{S}$, aunque los edificios se adaptaron a las necesidades constructivas y de disposición de la institución, que necesitaba agrupar los oratorios en un espacio determinado y cerrado sobre sí mismo. Sin duda influído por esta cercana construcción, debemos incluir también el oratorio de El Moncayo, situado a unos $3 \mathrm{~km}$ al sur del ribāt de Guardamar, de cronología similar y alineado aproximadamente a $180^{\circ}$ (García Menárguez, 2006) ${ }^{3}$. Aunque de datación dudosa, la mezquita de Velefique (Almería) propone también una orientación de tendencia meridional, con una dirección general en sentido SSE a 164 . El estudio arquitectónico y documental realizado por Sabine Angelé y Patrice Cressier (1990) a partir de los restos conservados del edificio apuntan a su construcción en el siglo X, similar a la de los anteriores dos ejemplos.

También vinculado a una cronología de finales del Califato cabe destacar el reciente caso documentado de la mezquita de alquería perteneciente al yacimiento arqueológico de La Graja (Higueruela, Albacete), orientada en este caso a $152^{\circ}$, una medida que la encuadra dentro del grupo de mezquitas orientadas también mediante la posición del orto solar durante el solsticio de verano (Jiménez Castillo, Simón y Moreno Narganes, 2021: 173-174).

Algo posterior es el caso de la mezquita rural de l'Almisserà (Vila Joiosa/Finestrat, Alacant), construida en el siglo XI en el punto intermedio entre tres alquerías, que la tomarían probablemente como aljama común (García Gandia, Llorens y Pérez, 2004). Su orientación, a $131^{\circ}$, parece acercarse más al grupo de templos de tendencia conciliadora, es decir, dispuestos con su alquibla hacia el SE, siendo ésta la referencia de compromiso entre las corrientes astronomistas y juristas. Dentro de

\footnotetext{
3. Actualmente, existe un proyecto de investigación arqueológica en el yacimiento de El Moncayo - Torre del Descargador, como parte de una iniciativa de colaboración entre el Ayuntamiento de Guardamar y el Instituto de Investigación en Arqueología y Patrimonio Histórico de la Universidad de Alicante (INAPH), con la colaboración de la Generalitat Valenciana y el Servicio Provincial de Costas.
}

esta misma tendencia, con una orientación de $142^{\circ}$, se encuentra el caso del oratorio rural que constituye uno de los elementos germinales en la construcción del hiṣn Turīš (Turís, Valencia). Con niveles fechados mediante análisis radiocarbónico y registro cerámico, su edificación ha quedado fijada a inicios del siglo XI (Jiménez Salvador, Díes y Tierno, 2014: 46). La mezquita de la fortaleza de Miravet (Cabanes, Castellón), un enclave defensivo bajo control de la ciudad de Tortosa, representa otro claro ejemplo de oratorio de cronología taifa. La orientación de este edificio, de unos $140^{\circ}$, vuelve a traernos a la mente esta misma tendencia de compromiso, que parece consolidarse como opción mayoritaria en el levante andalusí a lo largo del siglo $\mathrm{XI}^{4}$. Así parece corroborarlo también la mezquita de Sa Nitja (Es Mercadal, Menorca), orientada a $136^{\circ}$ y que aunque no ha podido ser datada con exactitud (Kirchner, 1999), en el contexto general balear y por la morfología de su mihrāab, parece adscribirse a esta misma cronología.

Aún sin disponer de una cronología precisa para el momento de su edificación, disponemos de un último ejemplo dentro de este grupo de mezquitas orientadas de forma general hacia el SE, como es el de La Xara (Simat de la Valldigna, Valencia). Se trata de un pequeño oratorio rural, destinado a dar servicio a una o varias de las alquerías cercanas y en el cual se distinguen dos momentos constructivos: uno fundacional, de cronología desconocida, y otro, que comportó importantes refacciones en el edificio y que se fecha a finales del siglo XV (Torró, 1995: 575). Su orientación, de $132^{\circ}$, resulta inexistente entre las mezquitas del siglo XII en todo al-Andalus, conociéndose casos posteriores únicamente en los territorios del reino nazarí, por lo que, a falta de nuevas evidencias arqueológicas, no sería descartable que este edificio hubiese sido alzado en época taifa, acorde con el resto de mezquitas orientadas en este sentido.

En época almorávide se edifica la mezquita rural de El Jarafí (Lanteira, Granada), un pequeño oratorio de una sola nave vinculado a una alquería y orientado a $121^{\circ}$, la misma dirección general que presenta el caso algo posteríor de la mezquita construida en la fortificación de Mojácar la Vieja (Mojácar, Almería) en época almohade, donde de nuevo encontramos un oratorio de una sola nave y orientado a $126^{\circ}$ (Martín Civantos et al., 2021). Por último, el ejemplo más tardío de que disponemos de mezquita rural en el Šarq al-Andalus es la de El Cortijo del Centeno (Lorca, Murcia), un pequeño oratorio rural orientado a $123^{\circ}$, edificado durante el período almohade y abandonado durante el tercer cuarto del siglo XIII, siendo destinado a dar servicio a distintas alquerías del entorno (Pujante, 2002: 77; Navarro y Jiménez, 2011: 115). En los tres casos anteriores, la orientación de estos oratorios es coincidente

\footnotetext{
4. Información planimétrica facilitada por el equipo arqueólogo redactor del Plan Director de la fortaleza, dirigido por Pablo García Borja y Joan Palmer.
} 


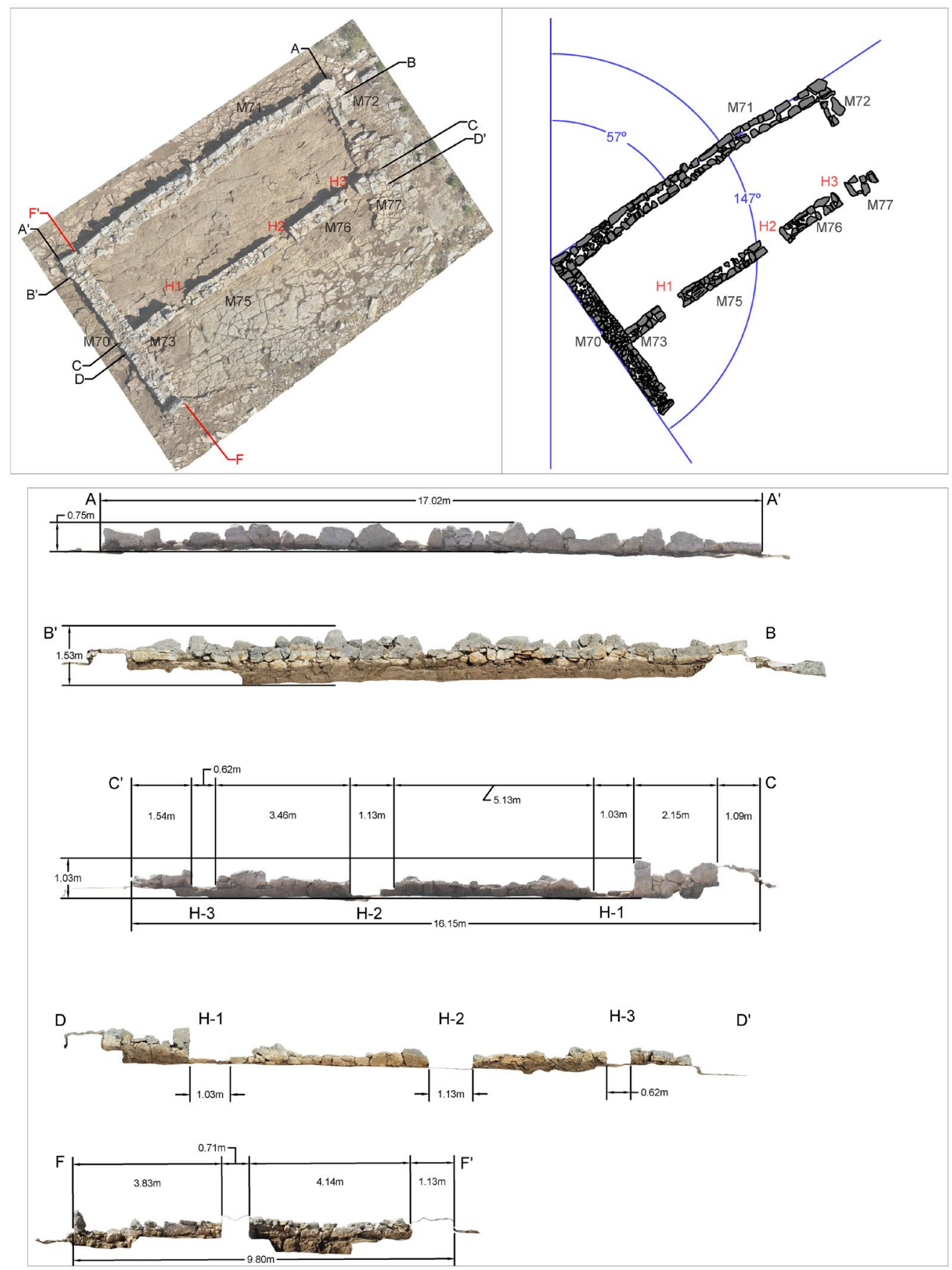

Figura 4: Planta de la mezquita con orientación general y secciones con alzados de los muros

con el orto solar durante el solsticio de invierno, que en este punto de la Península se produce aproximadamente a $120^{\circ}$. No se trata de una observación menor, pues el rechazo de almorávides y almohades a los métodos de la astronomía matemática y al compromiso generalizado respecto a la orientación SE se tradujo en un retorno a los métodos basados en la tradición, siendo los ortos solsticiales la opción más habitual usada en el diseño de sus mezquitas (Rius, 2000: 153-155).

Finalmente, en cuanto a nuestro caso de estudio, la mezquita del Tossal de la Vila muestra una orientación-de $147^{\circ}$, un cómputo altamente significativo, pues en las coordenadas estrictas en las que se encuentra el yacimiento, el orto solar durante el solsticio de verano es de $57^{\circ}$, dirección exacta hacia la que apunta el lado menor del edificio, lo que otorga al templo una orientación precisa respecto al orto de Suhayl (Fig. 4). Es ésta, por tanto, una mezquita orientada a imagen y semejanza de la tradición establecida desde la aljama cordobesa, un hecho que no resulta del todo trivial, pues se trata de la orientación elegida por algunos de los más importantes oratorios de época emiral, como los de la alcazaba de Badajoz, Almonaster la Real o la primitiva aljama de Niebla (Calvo, 2004: 49).

En cualquier caso, la orientación exhibida por la mayoría de mezquitas rurales de cronología omeya en 
el área del Šarq al-Andalus, nos lleva a considerar la posibilidad que los métodos de orientación más sencillos, basados en la dirección conocida del orto solar durante los solsticios, hubiesen sido los más generalizados durante este período. Pero, sobretodo, la constatación de la existencia de un oratorio en el Tossal de la Vila perfectamente orientado y monumentalmente construido, a pesar de lo recóndito, austero y precoz del contexto en el que se edificó, nos indica la presencia de un grupo de ocupantes con un grado de adhesión a las prácticas islámicas incuestionable. Se trata, no lo olvidemos, de una construcción levantada a finales del siglo VIII o inicios de la siguiente centuria, a más de dos semanas de camino desde Córdoba, y donde la autoridad más cercana, la de Tortosa, se encontraba a tres jornadas de viaje.

\subsection{MORFOLOGÍA GENERAL DEL EDIFICIO}

Toda la construcción se asienta sobre un nivel geológico de roca caliza, el cual fue desbastado mediante sucesivos frentes de cantera hasta conseguir una superficie prácticamente plana, sobre la cual descansa el edificio (Fig. 5).

Presenta una planta rectangular compuesta por dos módulos, la nave principal de la mezquita, de 17,02 x $5,27 \mathrm{~m}$ en su lado exterior y $15 \mathrm{x} 4 \mathrm{~m}$ en el interior, y un patio semiabierto de forma y proporciones simétricas a las del oratorio, apoyado sobre su costado sureste. La mezquita, de ejecución unitaria, se articula en base a la construcción de un muro de 9,80 m de longitud (M70), que limita tanto la nave del oratorio como el patio y de la prolongació ortogonal de su extremo hacia el NNE mediante diecisiete metros de muro (M71) sin ninguna apertura en el mismo, protegiendo el área principal de uso del edificio; un tercer paramento, del cual tan solo se conserva 1,70 $\mathrm{m}$ de su recorrido que parece haberse limitado al cierre de la nave principal del templo (M72); $\mathrm{y}$, por último, cuatro subtramos (M73, M75, M76 y M77) de una única unidad muraria, la cual se reconoce como la alquibla del templo (Fig. 8).

En cuanto a los tres hiatos que se describen en la alquibla, sus medidas y características no son coincidentes, hecho que nos ha llevado a proponer una lectura que toma en consideración estas diferencias y las interpreta en clave funcional.

Así pues, los dos espacios situados entre M73-M75 (H1) y M75-M76 (H2) presentan unas medidas de luz de 1,03 y $1,13 \mathrm{~m}$ respectivamente, encontrándose ambas aperturas a nivel geológico plano. Durante la excavación, también pudimos constatar en las inmediaciones de ambos hiatos diversos bloques de piedra de grandes dimensiones -en algunos casos de una longitud cercana al metro y medio- que se encontraban ligeramente desplazados de su posición original a causa de un posible intento de expolio moderno. En la cara externa de M76, junto a H2, se detectó además varios mampuestos de piedra perfectamente trabados con el muro, que debían formar parte, junto con los ortostatos desplazados, de una estructura de cierre de este espacio (Fig. 5). Los dos hiatos, por lo tanto, estarían sellados por dos pequeños muros que retranquerían el trazado de la alquibla exteriormente, conformando sendas hornacinas en el interior del oratorio, con unas medidas de aproximadamente $1,20 \times 1 \mathrm{~m}$. Todos estos indicadores

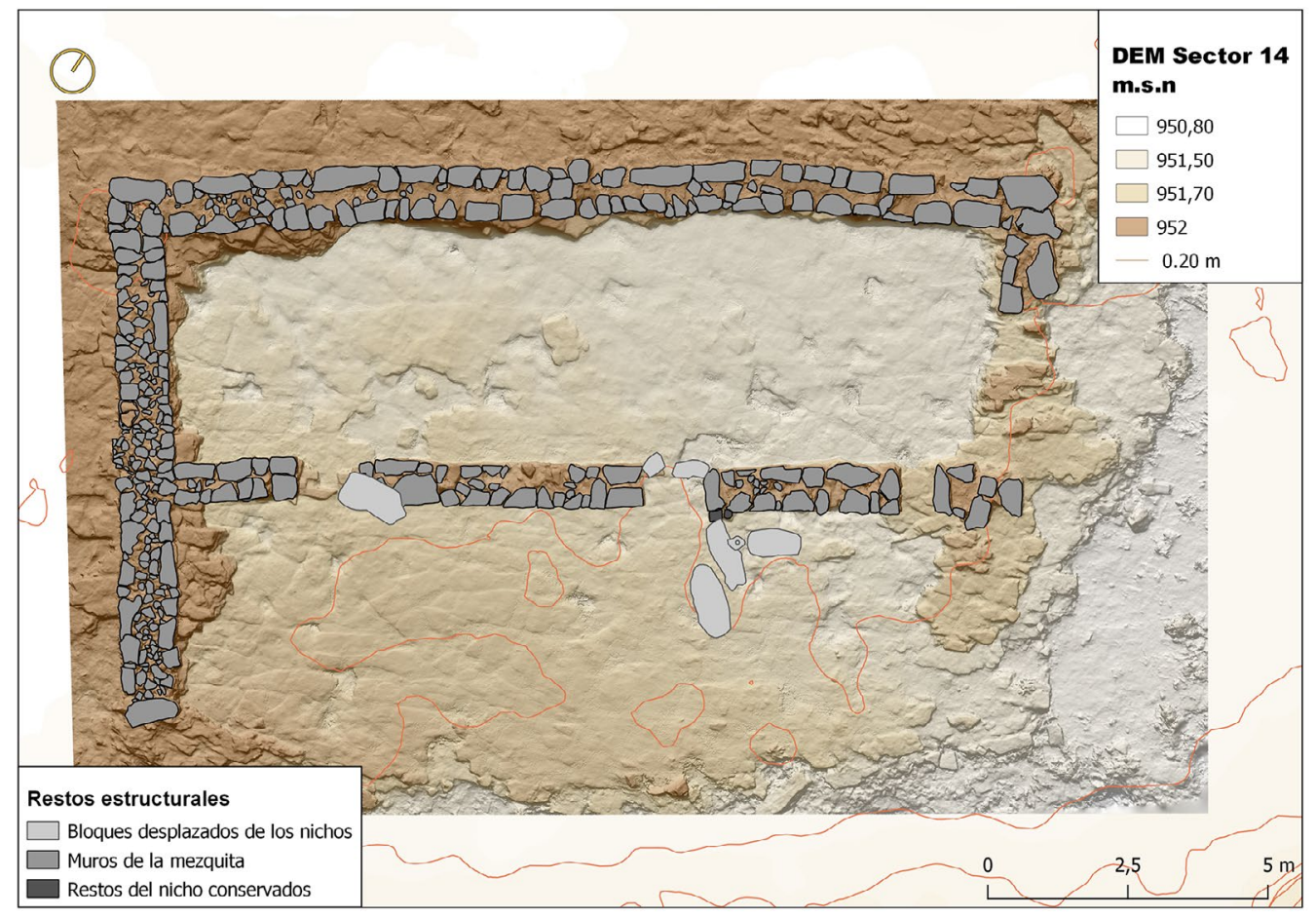

Figura 5: Planta de la mezquita sobre soporte geológico 
nos llevan a plantear que, en origen, estos nichos cumplirían la función de mihrāa, elemento arquitectónico cuyo propósito es señalizar la alquibla, planteándose de esta manera nuevos interrogantes que debemos bosquejar a modo de cuestión abierta.

Por cuanto refiere a su fisonomía, el mihrāb de planta rectangular resulta el más habitual en las mezquitas de cronología temprana (Calvo, 2014: 372-377), siendo éste el documentado en algunos ejemplos paradigmáticos del Šarq al-Andalus como son la rábita de Guardamar, La Graja de Higueruela o el Molón de Camporrobles, pero también en otros casos provenientes de distintos territorios peninsulares, como la alcazaba de Badajoz o la primera aljama de Zaragoza. En el caso del Molón, el más cercano cronológica y geográficamente a la mezquita del Tossal de la Vila, los nichos documentados -también dos-, muestran una solución arquitectónica idéntica y proporcionalmente análoga, definiendo un espacio interno de 1,50 x 1,25 m (Lorrio y Sánchez de Prado, 2008: 147).

Más compleja resulta la cuestión de la propia existencia de dos nichos, en lugar de uno, en la alquibla de nuestra mezquita, siendo una solución desconocida en el resto de al-Andalus hasta el momento. Es una problemática que también ha sido planteada para el ejemplo camporruteño, con el que no se comparten únicamente paralelismos en cuanto a localización y cronología, sino que ambos edificios parecen ser calcos exactos a nivel morfológico. El respeto por las proporciones y las similitudes a nivel de planta entre ambos edificios resultan tan significativas que representa un reto no buscar ciertos paralelismos entre ellos.

En cualquier caso, en el ejemplo del Molón se identificó, durante la excavación, un pequeño murete de época prerromana que dividiría el edificio en dos transversalmente, para el cual se ha planteado su reutilización durante la fase de uso de la mezquita (Lorrio y Sánchez de Prado, 2008: 148). Esto comportaría, según sus autores, la existencia de dos salas de oración separadas, de unos $28 \mathrm{~m}^{2}$ cada una de las cuales dispondría de su propio mihrāab. Aunque es una hipótesis sugerente para el ejemplo utielano, en el caso castellonense, después de su excavación sistemática, no hemos podido documentar ninguna estructura permanente de separación dentro de la nave, que compone un único espacio diáfano con dos nichos en la misma sala. Esta opción, según la cual pudiera existir más de un nicho en una misma alquibla, encuentra también un cierto apoyo en los trabajos de Juan Zozaya y Philip Banks en la fortaleza omeya de Gormaz (Soria), en la cual pudieron identificar hasta tres hornacinas en la cara sur de la muralla, relacionándolas con la existencia de una mușallà u oratorio al aire libre (Banks y Zozaya, 1984).

En un primer momento se planteó también la hipótesis de que el segundo nicho de la mezquita del Tossal pudiese corresponder a un pequeño espacio utilizado como encaje para un almimbar. Allí, pensábamos, podría situarse una pequeña estructura sobreelevada de madera desde donde el hațī $b$ del grupo residente en el yacimiento, como responsable de la prédica, realizaría la hutba o sermón del viernes, un momento clave de la oración comunitaria durante el cual se llevaría a cabo la declaración de apoyo y sumisión al poder central, transmitiendo posteriormente las órdenes de los gobernadores provinciales o del propio emir al resto de la comunidad. Se trata de una función que, a juzgar por la finalidad militar que otorgamos al recinto, parecía poder encajar adecuadamente con nuestro edificio. Además, arquitectónicamente, la existencia de nichos-habitáculos en los que ubicar el almimbar no era desconocida en las mezquitas rurales de al-Andalus más tardías, tal y como puede comprobarse en edificios como los de Mértola, el Cortijo del Centeno (Lorca) o La Xara (Simat de la Valldigna).

A pesar de todos estos indicios, se constata que este tipo de solución se introdujo en los oratorios de alAndalus a partir principalmente del siglo XI, momento al cual se atribuye la generalización del almimbar móvil (Calvo, 2014: 394-398), mientras que en cronologías más tempranas las fuentes escritas tan sólo recogen la existencia del púlpito fijo, tal y como atestigua el minbar de mampostería de la mușallà de Gormaz. Por lo tanto, a falta de nuevos indicios que apunten en otro sentido, consideramos que ambos nichos deben identificarse como maḥārīb y que la recitación de la hut tha se realizaría probablemente de pie frente a uno de ellos.

Dejando atrás la cuestión de las hornacinas, el tercer hiato de la alquibla el Tossal, localizado entre M76M77 (H3), presenta un vano mucho más reducido que los anteriores, de tan solo $62 \mathrm{~cm}$, y con el afloramiento de roca sin rebajar al mismo nivel del resto de la plataforma, definiendo así un pequeño escalón que protegería esta apertura de la entrada de agua o corrientes frías desde el exterior (Fig. 5). Todas estas características, sumadas a la similitud entre la luz de este hiato y la de las entradas de la mayoría de módulos construidos en el recinto, nos llevan a plantear la identificación de este espacio con el acceso a la nave principal. Es necesario destacar, sin embargo, que la existencia de una entrada a la mezquita en el muro de la alquibla no resulta tampoco la opción predominante en el mundo islámico, y aún menos cuando se trata del único acceso al oratorio. Sin embargo, y sin salir del Šarq al-Andalus, los ejemplos del Molón, Turís, La Graja, o la rábita de Guardamar presentan accesos en este mismo muro, aunque cabe destacar que en los dos primeros casos no se trata de la única entrada a la mezquita, y que en el último nos encontramos ante una solución vinculada a la propia topografía y evolución urbana del sitio.

A pesar de ello, en el caso de la mezquita del Tossal de la Vila defendemos la solidez de esta propuesta, que además se ve respaldada por la identificación, en la parte externa del acceso, de un nivel de losas planas de piedra caliza que, por su disposición, interpretamos como parte de un techado caído. Ello nos ha llevado a plantear la existencia de un pequeño soportal o porche de madera, más o menos abierto, que protegería la entrada principal y tal vez pudiese cumplir la función 


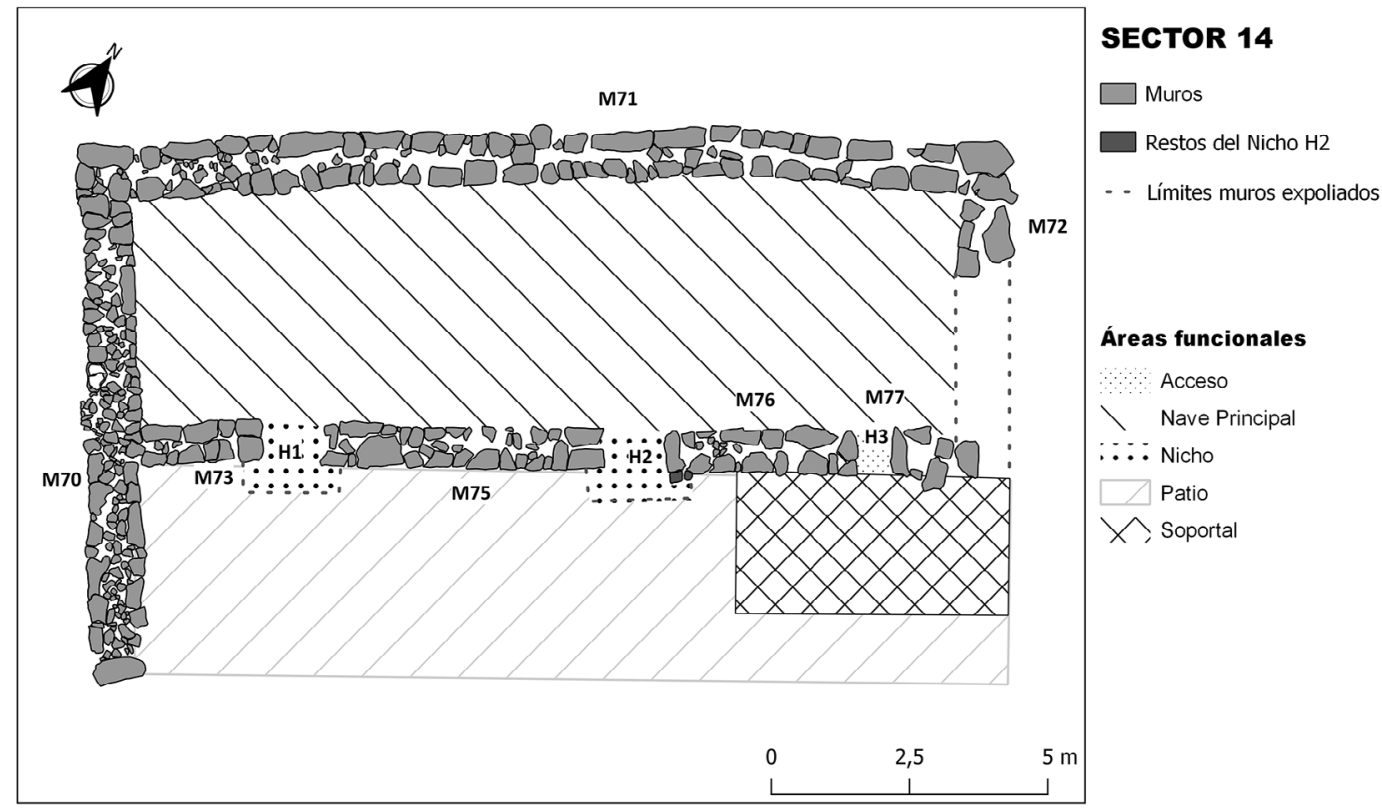

Figura 6: Planta funcional de la mezquita

de antesala donde realizar las abluciones previas a la entrada en el oratorio.

En resumen, son diversas las características morfológicas que han quedado ya bien fijadas en la descripción del oratorio del Tossal (Fig. 6). En primer lugar, la planta general del edificio, sobretodo en cuanto refiere a la nave principal y a la continuidad de uno de sus muros para cerrar el acceso y la visibilidad del patio desde el sector meridional del recinto fortificado. También las claras diferencias entre los dos hiatos murarios de dimensiones mayores, que identificamos como nichos con funciones sacras, y el más pequeño, que asociamos a la entrada a la nave principal de la mezquita. En tercer lugar, los evidentes paralelismos en cuanto a fisonomía general de nuestro edificio con el ejemplo de la mezquita del Molón, a excepción de la posible división en dos subsalas en el caso camporruteño, y la posición del patio, que en el caso del Tossal se ubica junto a la alquibla, es decir, en la entrada al templo. Y, finalmente, la existencia en nuestra mezquita de un espacio techado, probablemente construido con materiales perecederos y cubierto con ramas y losas de caliza, que serviría como antesala de acceso al oratorio.

\subsection{TÉCNICAS CONSTRUCTIVAS Y APAREJO}

La estructura general de todo el edificio estaría levantada sobre un zócalo de mampostería en seco formado por dos paramentos de bloques de tamaño grande y mediano perfectamente encajados entre sí, con un relleno entre ambos de piedras de menor envergadura y cascajo (Fig. 7). El hecho de no contar con ningún tipo de mortero en el rejuntado del zócalo -no hay indicios tan siquiera del uso de tierra que pudiese haber percolado a lo largo del tiempo- obligó a la construcción de unos muros de anchura mayor a la habitual para un edificio de una única altura. De esta manera, documentamos en estos paramentos una anchura media cercana al metro de espesor, con una altura conservada de entre una y tres hiladas de bloques, nunca superior al metro y siempre dispuesta directamente sobre el nivel geológico. Se trata de la técnica constructiva mayoritaria en el yacimiento, presente tanto en los zócalos de todas las edificaciones como en la muralla, y es uno de los rasgos distintivos de las construcciones de primera época andalusí en este territorio, donde el resto de ejemplos presentados cuentan con estructuras de idénticas características (Fig. 1).

El muro M71 es el que cuenta con el mayor número de grandes ortostatos colocados, utilizándose bloques de menor tamaño en la construcción de los lados menores M70 y M72, este último sin conservar sus dimensiones originales al hallarse expoliado. Estos grandes bloques se van a utilizar también en dos acciones constructivas diferentes: en la configuración de los mahārī̄b (en H2 se documentaron hasta tres de ellos aunque sin estar en su ubicación original, Figs. 5 y 8) y con función de refuerzo de final de tramo en M70. La ejecución de los muros perimetrales, cercanos al metro de amplitud, contrasta con la configuración del muro de la alquibla (M73, M75, M76 y M77), construido con bloques medianos perfectamente trabados y con una anchura de aproximadamente $70 \mathrm{~cm}$. En la cara exterior de este muro estarían apoyados sin trabar los grandes ortostatos que formarían el zócalo de los nichos, adquiriendo una mayor significación arquitectónica.

En general, los bloques que componen el zócalo no muestran indicios de trabajo o labrado, pero si parece haber una selección consciente de los mampuestos y una tendencia a la regularización de las alturas. Resulta remarcable el uso de los bloques de mayores dimensiones, en algunos casos colocados de forma transversal al sentido de los muros, en las esquinas del edificio, 

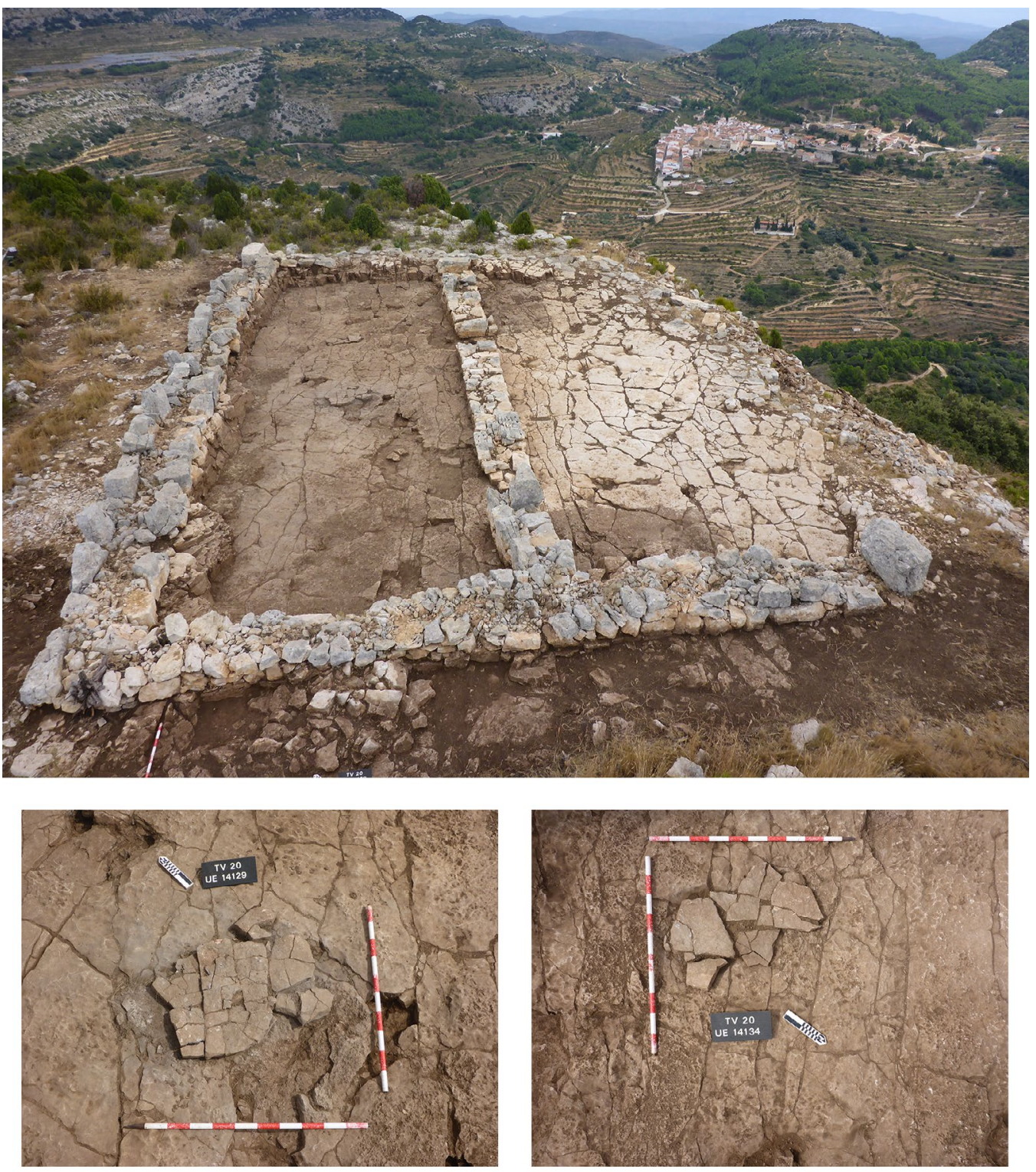

Figura 7: Imagen final de la excavación y detalle del enlosado

reforzando así la solidez del bloque constructivo en los puntos de traba entre lienzos. De la misma manera, M71 presenta una colección de extracciones rocosas ciclópeas dispuestas en sentido longitudinal, una solución indicada para un mayor aislamiento de la cara norte respecto al frío y el viento, así como para el asiento del propio volumen de la mezquita, que tendría en M70, M71 y M72 sus principales ejes estructurales, dando mayor libertad de cargas y empujes a la alquibla, donde se situarían los distintos hiatos destinados a los mahārīb y la entrada. Aunque el conjunto del zócalo se dispone sobre el suelo geológico correspondiente al afloramiento de caliza, se refuerza su estabilidad en algunos puntos mediante el uso de una capa de gravas y tierra bastante uniforme que lo sostiene.

Por encima del basamento pétreo se levantarían las paredes del edificio que, al igual que en el resto de construcciones del yacimiento, están realizadas con tierra, probablemente mediante encofrado, tal y como ha podido documentarse durante la excavación de los niveles de derrumbe. No es descartable que durante su construcción también se recubriera la cara externa de los zócalos con tierra, con la finalidad de impermeabilizar la nave principal, aunque no se conservan evidencias de ello por la fragilidad de estos acabados. La cubierta del edificio estaba realizada mediante viguetas o troncos de madera, cubiertos con ramas, una lechada de tierra y losas planas de piedra caliza del entorno. Este acabado le daría al mismo tiempo una cierta ligereza y la protección necesaria ante una climatología que, a una altura de casi $1000 \mathrm{~m}$ y en un período de temperaturas más bajas que las actuales, sería exigente en cuanto a precipitaciones en forma de nieve.

En el interior de la mezquita no se ha podido documentar ninguna estructura doméstica, hogar, o similar, y son prácticamente inexistentes los materiales 
arqueológicos en posición primaria. El nivel de circulación se realizaría por encima del suelo geológico, completamente llano tras la extracción de bloques mediante frentes de cantera (Fig. 5). Los intersticios entre las distintas vetas de caliza, estarían rellenos con gravas y tierra, además de algún pequeño y erosionado fragmento cerámico, tanto de época andalusí como de las fases protohistóricas. Algunos sectores del interior de la mezquita contaron con un enlosado de buena calidad, bien encajado y ligado mediante tierra, aunque no parece haber sido una solución desarrollada en toda la superficie de la nave (Fig. 7). Finalmente, es probable que el suelo contara con un fino nivel vegetal, de paja o similares, para aislar el nivel de circulación de la humedad y el frío acumulados sobre el nivel geológico.

En aquellos sectores en que el recorte del frente de cantera no se había aplomado respecto a los muros del edificio, especialmente en los tramos de intersección entre M70 y M71, se documentan también restos de una posible capa de enlucido o revestimiento que habría cubierto estos afloramientos rocosos en el interior del oratorio, probablemente para ser utilizados como banquetas. Resulta destacable, también, la presencia de niveles de cenizas tamizadas, sin carbones ni impurezas, en algunos puntos del edificio. Se trata de acumulaciones para las cuales carecemos de una explicación unívoca, aunque podrían estar relacionadas con la quema de inciensos o braseros para la regulación térmica del ambiente.

\subsection{SECUENCIA ESTRATIGRÁFICA}

La construcción inicial del edificio corresponde a los primeros momentos de la fase III, el inicio de la ocupación andalusí tras un enorme hiato que arranca desde las anteriores fases protohistóricas, mientras que su incipente abandono se refleja en la subfase III.1 con el colapso final a lo largo de la fase IV, según la periodización general del asentamiento (Fig. 9). Sus restos, aislados y sin conexión aparente con ningún otro sector, se localizan en un espacio alejado tanto del núcleo habitacional como de las dependencias auxiliares destinadas al almacenaje y estabulamiento.

El proceso de edificación empieza por la elección de un frente de cantera natural desde donde iniciar la extracción de los bloques que se aprovecharían para el alzamiento de los paramentos principales M70, M71 y M72 (Fig. 8). Sobre este frente de extracción se levantaron los zócalos pétreos, dejando una superficie lo suficientemente plana a sus espaldas para su posterior reacondicionamiento. El recorte aplomado del frente de cantera se evidencia sobretodo en los tramos de intersección entre los muros M71 y M72, mientras que en el extremo de M71 en su unión con M70 el desbaste del frente de cantera será menos cuidado, contando con indicios que apuntan a la existencia de un revestimiento del afloramiento rocoso hasta la altura en que se coloca la primera hilada del zócalo (Fig. 8).
La secuencia constructiva (Fig. 9), determinada en función de las relaciones estratigráficas entre las cuatro grandes unidades murarias, señala que fue el costado menor de la mezquita (M70), seguido de su ortogonal extremo (M71) los que primero se levantaron, adosándose a ellos finalmente el costado menor NE (M72) y, finalmente, los diferentes tramos de la alquibla (M73M77). Esta constatación parece confirmar la hipótesis ya planteada sobre la orientación de la mezquita, que tomaría el orto solar durante el solsticio de verano como referencia para sus costados menores, alineando así ortogonalmente la alquibla hacia el orto de Suhayl. Con este trazado sumario, la nave principal de la mezquita dispondría de unos $60 \mathrm{~m}^{2}$ útiles en su interior, con un patio semiabierto y limitado únicamente por el muro M70 al suroeste y por el acantilado que fija el perímetro oriental del yacimiento.

El edificio inicial quedaría finalizado, como ya hemos indicado, con un nivel de suelo enlosado, el cual ha llegado hasta nuestros días muy alterado (UE 14126), con una mínima superficie conservada in situ (UE 14129 y UE 14134, Figs. 6 y 7). A tenor de los resultados obtenidos, no se puede confirmar la extensión de esta solución de empedrado con losas planas bien encajadas a todo el espacio, dejándose entrever al menos que podría haberse ejecutado en el espacio presidido por ambos nichos, justo desde donde se documentan los restos de los posibles enlucidos caídos (UE $14131,14132,14133$ y 14135). El estado de los restos conservados hace imposible una interpretación inequívoca al respecto.

Por lo que respecta al contexto de uso (Fig. 8: Fase III), no existen estructuras asociadas a actividades domésticas o artesanales, siendo el único indicio de acción antrópica un pequeño depósito de cenizas cribadas (UE 14128), asociables al enlosado 14129 y cuya existencia plantea la posibilidad de hallarnos ante los restos de actividades relacionadas con la calefacción del ambiente mediante el uso de brasas o ascuas producidas en un hogar externo al oratorio, como ha sido anteriormente propuesto en el texto.

La vida del edificio se caracteriza por el progresivo deterioro del espacio de culto y una reorientación en el uso del patio exterior (Fase III.1) que finalizará con el definitivo abandono y expolio de la mezquita a partir de las décadas centrales del siglo siglo X (Fase IV). Aunque podamos contrastar el deterioro de sus estructuras, asistimos a la remodelación espacial del patio posiblemente vinculado a un uso específico por determinar en base a la construcción de un pequeño ámbito adosado a M70 y M73 de unos $5 \mathrm{~m}^{2}$ (Fig. 8: Fase III.1). Aunque ha llegado a nuestros días alterado se puede reconocer la disposición de sus muros de cierre M74 y M78, con la entrada dispuesta entre este último paramento y M73 medienate un unmbral (UE 14305). Este espacio se rematará en parte para regularizar el nivel de uso con la aportación de un paquete de tierra (UE 14303) sellado seguramente por losas planas (UE 14302). 


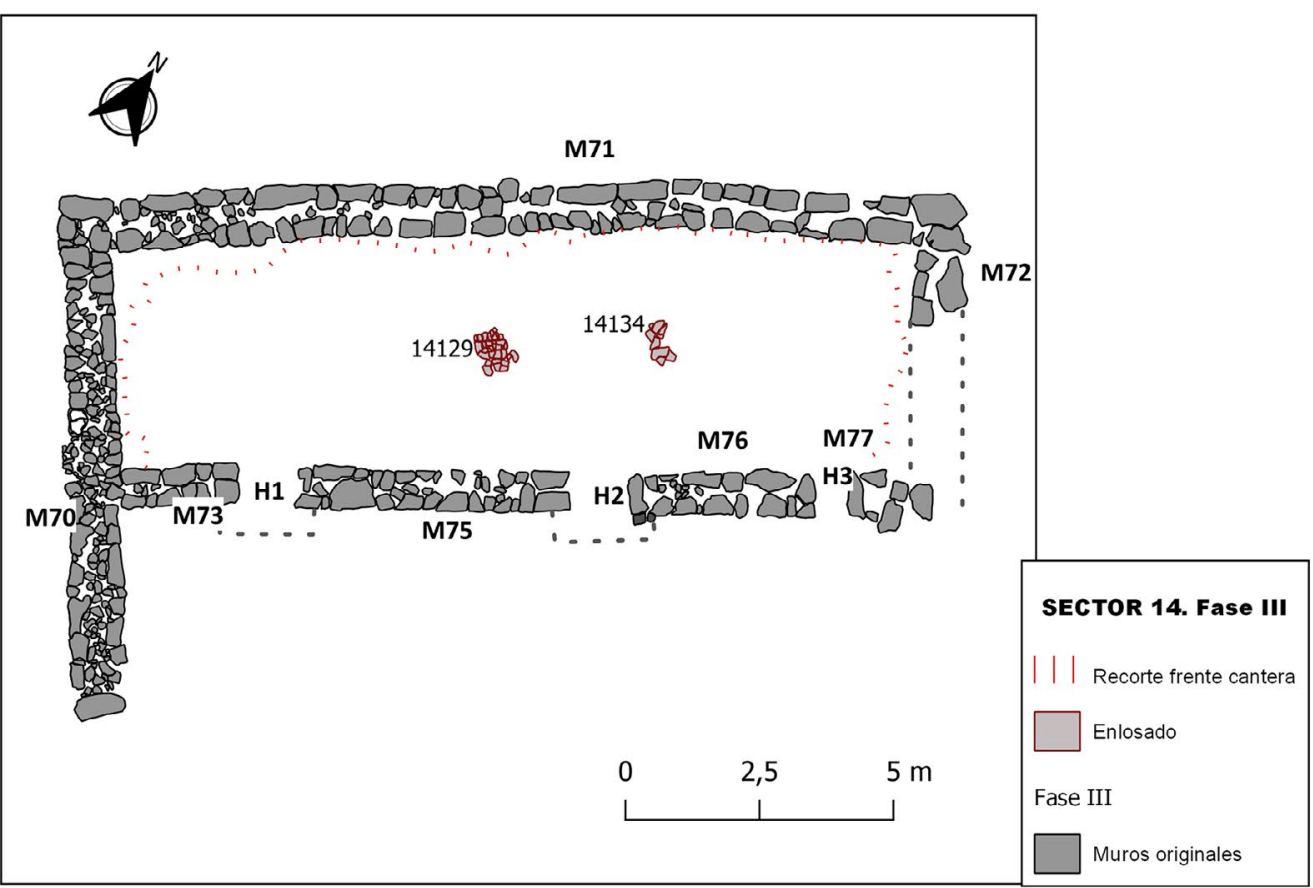

Restos del Nicho $\mathrm{H} 2 \quad$ - L Límites muros expoliados

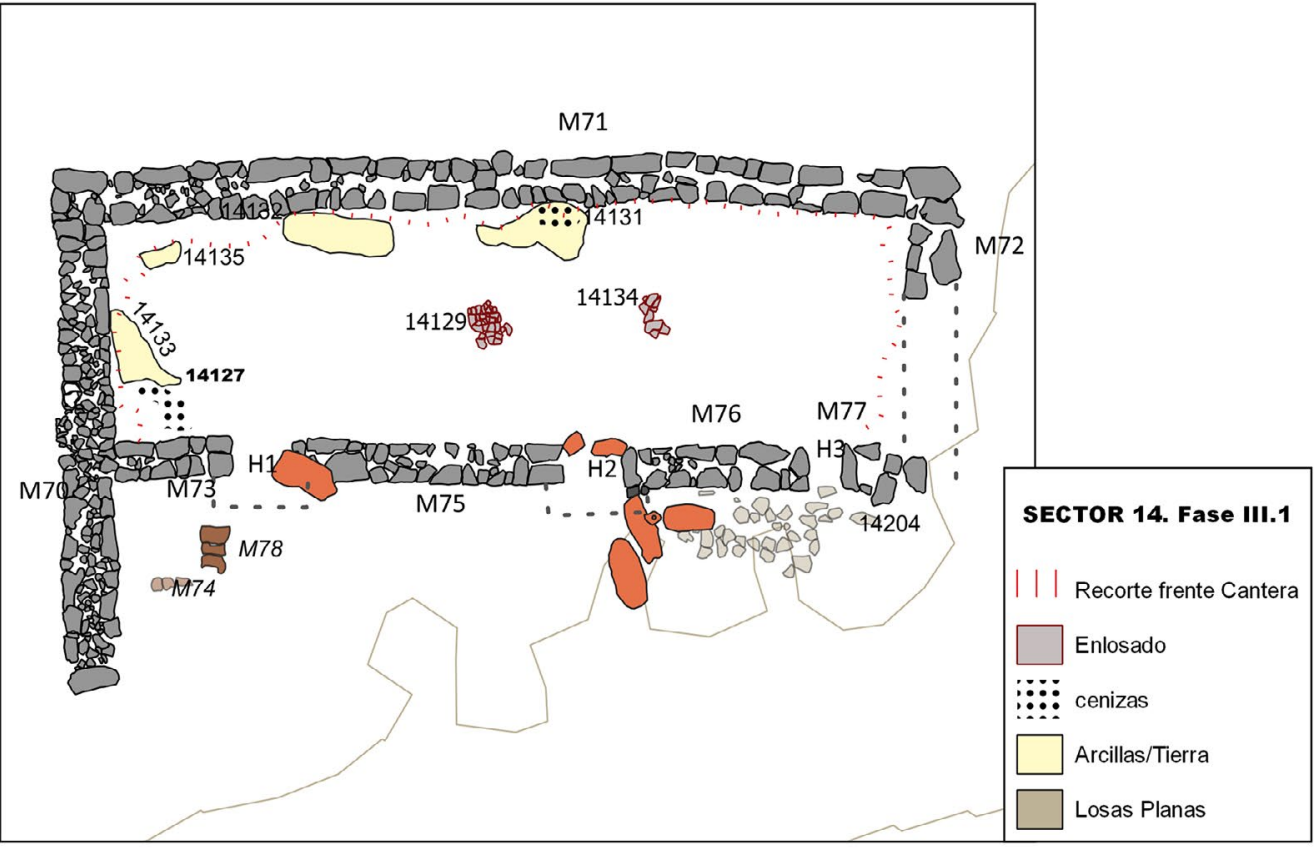

Bloques alterados

Figura 8: Plantas del momento de uso de la mezquita y el momento de amortización

Resulta difícil definir el uso que se le dio a este pequeño espacio y si está asociado al edificio de culto. La forma constructiva de sus paramentos contrasta con la técnica edilicia de la mezquita, siendo sus muros de mucha menor entidad. Quizá a este momento podamos asociar el deterioro del interior de la mezquita, con los enlucidos caídos y el enlosado sin reacondicionar. En el patio, al margen del acondicionamiento de un nuevo espacio también encontramos los primeros signos de abandono del edificio, con la progresiva acumulación de tierra sobre la superficie del nivel de uso que acabará con la definitiva caída de la cubierta del soportal de entrada.

4. APORTACIONES AL DEBATE SOBRE LAS MEZQUITAS RURALES DEL ŠARQ AL-ANDALUS

Es poca, y en muchos casos aderezada con tintes apologéticos, la información que las fuentes escritas nos ofrecen en relación a la construcción, funciones y 


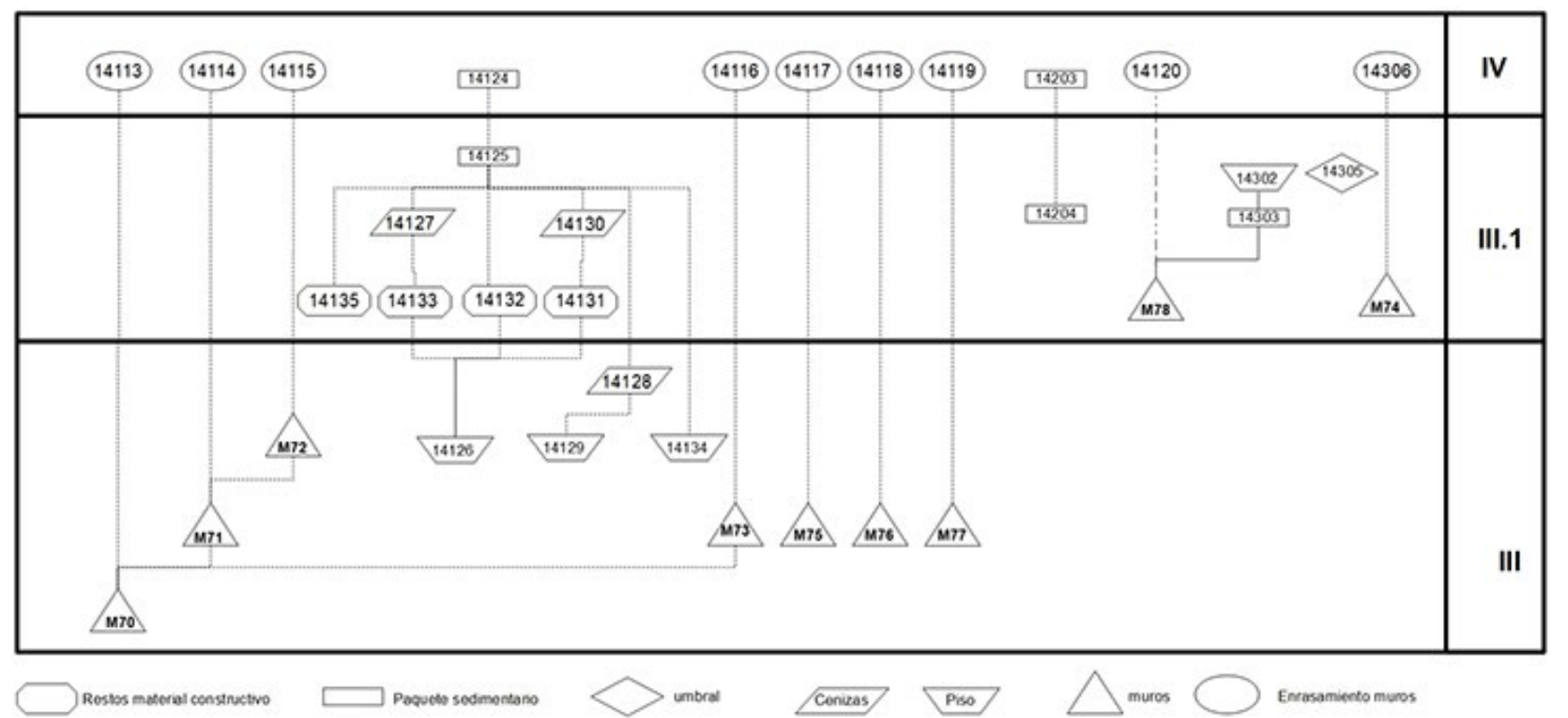

Figura 9: Diagrama representativo de la secuencia estratigráfica del sector 14

evolución de las mezquitas andalusíes durante el emirato (Calvo, 2020: 31). Si nos desplazamos al ámbito rural, vemos como los datos disminuyen de forma significativa, desarrollándose el conocimiento sobre estos edificios a partir de lugares comunes, analogías $\mathrm{y}$, en el peor de los casos, sobre historiografía previa, creando argumentos circulares que terminan por convertirse en grandes castillos de naipes. Así pues, cabe admitir que la información que los textos árabes nos aportan en torno a la expresión material del islam en el medio rural se reduce a unas pocas menciones tardías de fetuas o dictámenes jurídicos, cuya aplicación no se retrotrae más allá del siglo XI. Son, entre otras, las conocidas fetuas de Ibn Rušd (m. 1126) en relación a la construcción comunitaria de una mezquita por parte de los habitantes de varias alquerías vecinas, o el uso por parte de estas mismas comunidades del oratorio de una fortaleza cercana durante la fitna (Lagardère, 1993: 176-177). De esta manera vemos cómo, a partir de un dictamen recogido en el siglo XII y apoyándose sobre modelos historiográficos preconcebidos, se ha ido construyendo una visión homogénea sobre la construcción de mezquitas en el ámbito rural y su papel en el proceso de islamización religiosa que no se corresponde con la realidad material que poco a poco va viendo la luz.

$\mathrm{Y}$ es que, gracias al aumento de casos de estudio excavados o documentados, la pequeña fracción de mezquitas rurales del Šarq al-Andalus que conocemos nos permite ahora establecer algunas pautas generales que emergen de su análisis. Por ejemplo, en cuanto a su patrocinio, podemos distinguir entre tres grupos claramente diferenciados: aquellas vinculadas al fenómeno del ğihād costero, como serían las de Guardamar del Segura y el Moncayo; las que fueron impulsadas para dar servicio a fortificaciones, tanto con poblamiento permanente anexo a ellas, como el Molón, Juviles, Miravet o Mojácar la Vieja, como para guarniciones de carácter marcadamente militar, pues tal es el caso del Tossal de la Vila y de la primera fase de Turís, cuando se construye su oratorio (para el cual el equipo que lo excavó propone una adscripción como zāwiya con enterramiento de un destacado personaje musulmán); $\mathrm{y}$, finalmente, aquellas vinculadas a dar servicio a una o varias alquerías de su alrededor, como sucede en los casos de La Graja, Velefique, Almisserà, La Xara, Sa Nitja, El Jarafí o El Cortijo del Centeno. Tan solo contrastando esta primera categorización y las cronologías con las que se trabaja para cada uno de los ejemplos, todo apunta hacia una primer difusión del islam en la periferia de al-Andalus durante el siglo IX, a través de centros vinculados a algún tipo de poder o autoridad, bien fortificaciones, bien rubuṭ. En cambio, son más tardíos los ejemplos de mezquitas rurales vinculadas a alquerías, aldeas u otros centros de poblamiento campesino, que en la mayor parte de los casos corresponden ya a época taifa o posterior.

En cuanto al primer grupo, el de los casos relacionados con instituciones religiosas o recintos fortificados, sus características morfológicas resultan además bastante similares, tratándose de oratorios de una única nave, de tendencia rectangular, longitudinal respecto a la alquibla y con una superfície útil alrededor de los $20 \mathrm{~m}^{2}$, en los ejemplos religiosos, y cercana a los $60 \mathrm{~m}^{2}$, en los puramente militares. Por otra parte, los ejemplos de mezquitas rurales vinculadas al servicio religioso de una o varias alquerías, presentan unas características totalmente diferentes a las anteriores, aunque también fuertemente homogéneas entre sí. Con la excepción del temprano caso de La Graja, morfológicamente similar al resto de mezquitas de cronología omeya de una sola nave, nos encontramos con templos de planta tendente a la cuadrangularidad, que cuentan con tres naves, dispuestas perpendicularmente a la alquibla y con una superficie útil de entre 100 y $120 \mathrm{~m}^{2}$. Resulta como 
mínimo destacable la regularidad en las características constructivas y fisionomía de las mezquitas rurales del territorio levantino de la Península.

Un último elemento a remarcar, como ya hemos incidido en el apartado correspondiente de este texto, es el de la orientación de estos oratorios, que parece seguir unas ciertas pautas bastante consistentes. De esta manera, las alquiblas de las mezquitas más arcaicas, construidas durante el período emiral o califal, parecen haberse levantado siguiendo unos parámetros vinculados a criterios astronómicos de fácil transmisión y arraigo, bien guiados por el orto del solsticio invernal o por la perpendicular al orto del solsticio estival. En cambio, el conjunto de oratorios del ribāt califal de Guardamar o el del Moncayo deben entenderse como un caso específico con una orientación general hacia el sur, siguiendo una tradición local establecida a partir de la mușallà emiral, aunque adaptada totalmente al urbanismo del recinto. En total, cuatro tipos diferentes de orientación de entre los siete ejemplos documentados durante los momentos formativos del islam andalusí en el Šarq, atendiendo tanto a criterios de posicionamiento astronómico como a la tradición y pautas locales.

Esta heterogénea situación daría un súbito cambio con la consolidación de la formación social islámica en la Península, que condujo al mismo tiempo hacia una adopción mayoritaria del islam y una cierta formalización de sus preceptos generales. Entre otras pautas, debió fijarse la orientación general acceptable de la alquibla, que en el caso de los ejemplos rurales de los territorios mediterráneos de al-Andalus parece que se estableció dentro de una horquilla general en sentido SE, una tendencia de consenso entre direcciones tradicionales de sentido meridional y las distintas pautas astronómicas basadas en los ortos solsticiales y equinocciales. Y es que, entre $131^{\circ}$ y $142^{\circ}$ se encuentra la orientación de la alquibla en absolutamente todas las cinco mezquitas rurales levantinas de cronología taifa documentadas, contra la cual abogaron almorávides primero y almohades después, como bien ejemplifican los casos de El Jarafí, Mojácar la Vieja o El Cortijo del Centeno, que de nuevo recuperan el uso del alba invernal. Con todo esto, y a pesar de la falta aún de más casos de estudio con que contrastar estas primeras observaciones, el escenario planteado muestra unas pautas comunes y unas transformaciones a lo largo del tiempo que apuntan hacia una historia de las mezquitas rurales del Šarq al-Andalus mucho más rica y compleja de lo que se ha descrito hasta el momento, con realidades particulares de gran interés para entender el proceso formativo de la sociedad andalusí en su periferia.

$\mathrm{Y}$ uno de esos casos singulares es el que encontramos en el Tossal de la Vila, un importante recinto fortificado pero que no presenta evidencia alguna de haber concentrado un poblamiento anexo permanente o servido de refugio de ninguna comunidad campesina cercana. Una fortaleza con mezquita que responde, a pesar de sus similitudes cronológicas y morfológicas, a un marco de referencia diferente al del Molón, donde sí parece existir un asentamiento estable de población segregado del núcleo militar. Y diferente también al caso del ribāt de Guardamar, por más elementos en común que presenten entre ellos. Tal vez ésta sea la clave interpretativa a tener en cuenta, la de mostrar una realidad mucho más heterogénea a lo largo del proceso formativo de al-Andalus de lo que lo será tras su consolidación.

\section{CONCLUSIONES}

Conviene describir nuestro caso de estudio a partir de la única fuente que ha sido capaz de aportarnos información sólida y fiable: el registro arqueológico. Un informador poliédrico que recoge distintas facetas de un mismo problema, desde la plasmación arquitectónica de unas técnicas constructivas de posible desarrollo local, hasta la expresión material de una práctica de profunda significancia religiosa como es la orientación de este edificio. En este texto hemos recogido todos los elementos que convierten el oratorio estudiado en un ejemplo útil para desarrollar un estudio comparativo entre este tipo de edificios religiosos dentro de nuestro ámbito de trabajo.

En el caso que nos ocupa, y a partir del análisis de diversos factores que consideramos coincidentes con nuestra hipótesis, proponemos la identificación del edificio del sector 14 del Tossal de la Vila como una mezquita comunitaria. Un oratorio que tendría un papel central en esta fortificación, construida por un grupo militarizado cuya identidad u obediencia nos es aún esquiva, y que la ocuparía con el objetivo de cumplir unas funciones probablemente vinculadas a la vigilancia viaria y costera, así como al control territorial (Negre et al., 2020a). Entendemos, además, que la orientación del muro de la alquibla se realizó mediante métodos relativamente sencillos vinculados a la astronomía popular, en este caso orientando el lado menor del edificio hacia el orto del Sol durante el solsticio de verano. Una operación que podría haber realizado cualquier persona con unos conocimientos mínimos de posicionamiento, pero con una elección del criterio de orientación que coincide con la adoptada en la capital omeya y en muchas de las mezquitas alzadas bajo su égida.

La voluntad de proteger la visión del patio de la mezquita desde el resto del recinto explica también la longitud desigual entre los lados paralelos M70 y M72, siendo el primero de ellos significativamente más prolongado e interponiéndose entre el área de acceso y los sectores de estabulación y almacenaje del recinto. El acantilado, ligeramente más retirado de lo que se observa en la actualidad, serviría como límite de esta zona abierta y un pequeño soportal de madera con techado de ramas y losas de piedra haría a su vez de antesala de acceso al edificio, donde los creyentes podrían prepararse antes de entrar en el oratorio. 


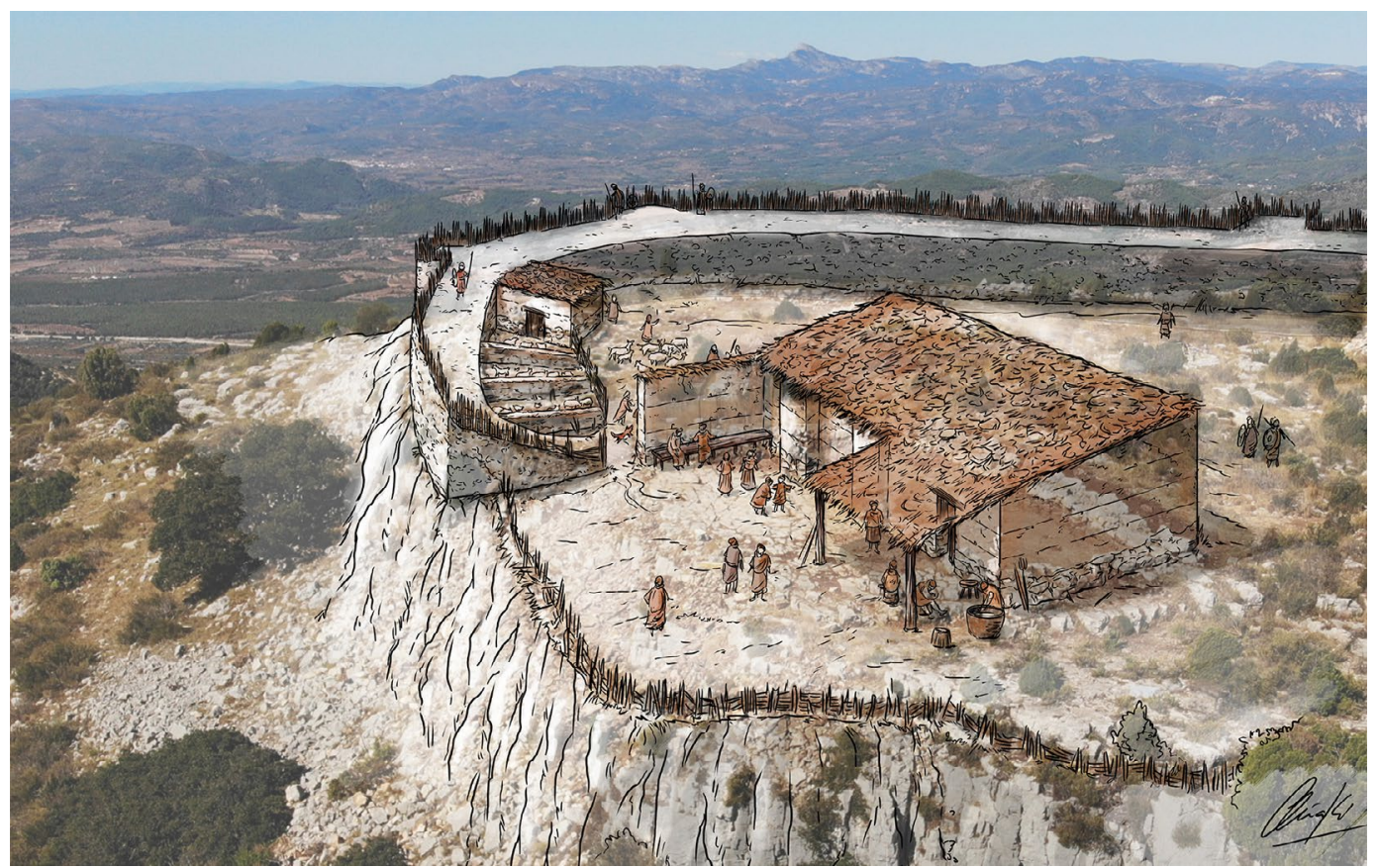

Figura 10: Ilustración idealizada de la mezquita del Tossal de la Vila (Autor: Iñaki Diéguez)

En cuanto a los nichos presentes en la alquibla, mantenemos abierta la posibilidad de que la presencia de dos de estas hornacinas pudiese deberse a una práctica arcaica aún por definir vinculada al uso de más de un mihrāa $b$ al mismo tiempo, sin descartar la opción de la compartimentación en dos salas de la mezquita. En el caso del Molón esa parece ser la explicación más adecuada, si atendemos a la presencia de un pequeño muro de la fase pre-islámica reaprovechado como tabique entre estos dos espacios. Para el Tossal no hemos documentado ninguna solución similar, aunque el uso de materiales perecederos de forma generalizada en el yacimiento (Negre et al., 2020b: 158) podría explicar también un posible cierre en dos salas separadas por una divisoria de madera. Explicar la necesidad de esa separación se escapa a nuestras posibilidades en estos momentos, pero consideramos que se trata de un elemento de debate interesante y con posibilidad de desarrollo.

Desde una perspectiva más global, resulta de gran importancia empezar a poner en relación estos primeros edificios religiosos rurales, como nuestro caso de estudio o el identificado en la fortaleza del Molón, con una serie de características que parecen ser comunes entre ellos. Hablamos de rasgos como su planta y proporciones, de una sola nave de tendencia rectangular y disposición longitudinal respecto al muro de la alquibla, con un espacio útil siempre cercano a los $60 \mathrm{~m}^{2}$; una ausencia generalizada de estructuras domésticas y de registro arqueológico en posición primaria; la irresoluta presencia de más de un mihrāa b en la alquibla; el uso de aparejos locales, como la mampostería en seco o con mortero de barro, mediante dos paramentos rellenos con cascajo y reforzados en sus esquinas con grandes bloques de piedra; e, incluso, el uso de unos métodos de orientación comunes vinculados a la astronomía popular, es decir, sencillos parámetros de fácil difusión y aplicación.

A pesar de las coincidencias entre estas dos primitivas mezquitas, seguimos observando como sus particularidades plantean más interrogantes que aseveraciones. ¿Cuál era la función de un doble mihrāa en una misma alquibla, presente en ambos casos, pero también en otros ejemplos más alejados, como la mușallà de Gormaz o diversos oratorios orientales de época omeya (Walmsey y Damgaard, 2005: 370; Calvo, 2010: 288)? ¿Podemos relacionar la orientación de la mezquita del Tossal, a imagen y semejanza de los criterios de la aljama cordobesa, con una influencia estatal en su construcción o más bien con una práctica de astronomía popular extendida entre los primeros musulmanes andalusíes? ¿Representa la construcción mediante mampostería en seco durante el emirato una particularidad local en uso en diferentes espacios sin relación entre sí o se trata de un elemento capaz de identificar a una comunidad específica en el origen de su aplicación y generalización?

Dejando abiertas estas cuestiones, nuestra interpretación de la mezquita del Tossal y del contexto en el cual se construyó y al cual debe las funciones específicas que cumpliría es tan solo una lectura del escenario más plausible en función de las evidencias materiales y documentales de las que disponemos. No se trata, ni mucho menos, de una propuesta cerrada o excluyente. Con los exiguos ejemplos de que disponemos en todo al-Andalus, aún más insignificantes cuando reducimos el ámbito de estudio al territorio levantino de la Península en época emiral, no podemos más que exhortar al debate y a la presentación de nuevos casos de estudio que permitan, a medio plazo, dibujar un nuevo paisaje historiográfico que aporte mayor luz a 
la problemática de las tempranas mezquitas en el medio rural andalusí. Mientras tanto, sirva nuestro trabajo para incitar a una discusión constructiva sobre los argumentos presentados.

\section{AGRADECIMIENTOS}

Los autores del texto quieren agradecer de antemano la revisión del manuscrito realizada por Sonia Gutiérrez Lloret, Susana Calvo Capilla y Rafael Azuar Ruiz, cuyos acertados comentarios y sugerencias a buen seguro han mejorado el texto final. También reconocer el inagotable trabajo de todo el equipo técnico de arqueólogas y arqueólogos que año tras año hacen de La Serra d'en Galceran y del yacimiento del Tossal de la Vila su casa.

\section{REFERENCIAS}

Aguilella, G., Falomir, F., Pérez, G., Laguna, M., García, D. A. y Arquer, N. (2016). Tossal de la Vila (Serra d'en Galceran, Castellón). Un asentamiento en la transición del Bronce Final al Hierro Antiguo. Quaderns de Prehistòria i Arqueologia de Castelló, 34, 5-41.

Angelé, S. y Cressier, P. (1990). Velefique (Alméria): un exemple de mosquée rurale en al-Andalus. Mélanges de la Casa de Velázquez, 26(1), 112-130. DOI: https://doi. org/10.3406/casa.1990.2562

Azuar, R. (2004). El ribât en al-Andalus: espacio y función. 'Ilu. Revista de Ciencias de las Religiones, 10, 23-38.

Azuar, R. (Ed.). (2004). Fouilles de la Rábita de Guardamar I. El ribât califal. Excavaciones e investigaciones (19841992). Madrid: Casa de Velazquez.

Bazzana, A. (1992). Maisons d'Al-Andalus. Habitat médiéval et structures du peuplement dans l'Espagne orientale. Madrid: Casa de Velázquez.

Banks, P. y Zozaya, J. (1984). Excavations in the Caliphal Fortress of Gormaz (Soria), 1979-1981: A Summary. En T. F. Blagg, R. F. Jones y S. J. Keay (Eds.). Papers in Iberian Archaeology (vol. II, pp. 674-704). Oxford: British Archaeological Reports.

Calvo, S. (2004). Las mezquitas de pequeñas ciudades y núcleos rurales de al-Andalus. 'Ilu. Revista de Ciencias de las Religiones, 10, 39-63.

Calvo, S. (2010). Analogies entre les grandes mosquées de Damas et Cordoue: mythe et réalité. En A. Borrut y P. M. Cobb (Ed.). Umayyad Legacies. Medieval Memories from Syria to Spain (pp. 281-311). Leiden: Brill. DOI: https://doi. org/10.1163/ej.9789004184749.i-560.72

Calvo, S. (2014). Las mezquitas de al-Andalus. Almería: Fundación Ibn Tufayl.

Calvo, S. (2020). Los inicios de la arquitectura religiosa en al-Andalus y su contexto islámico. Studia historica: Historial medieval, 38(1), 29-57. DOI: https://doi.org/10.14201/ shhme20203812957

García Gandia, J. R., Llorens, S. y Pérez Botí, G. (2004). L'Almisserà: territorio castral y espacio rural en época islámica. En F. J. Jover y C. Navarro Poveda (Coords.). II Jornadas de Arqueología Medieval. De la medina a la villa (pp. 83-105). Alicante: Museo Arqueológico Provincial de Alicante.

García Menárguez, A. (2006). Dades preliminars sobre la ràpita andalusí del Moncaio. La Rella, 19, 227-245.

Gutiérrez Lloret, S. (2012). Gramática de la casa. Perspectivas de análisis arqueológico de los espacios domésticos medievales en la península Ibérica (siglos VII-XIII). Arqueología de la Arquitectura, 9, 139-164. DOI: https://doi.org/10.3989/ arqarqt.2012.11602

Jiménez, A. (1991). La qibla extraviada. Cuadernos de Madinat al-Zahra', 3, 189-209.

Jiménez Castillo, P., Simón, J. L. y Moreno Narganes, J. M. (2021). La alquería andalusí de La Graja (Higueruela). Poblamiento y economía campesina en la Mancha oriental. Albacete: Diputación de Albacete. DOI: http://doi. org/10.37927/978-84-18165-45-0

Jiménez Salvador, J. L., Díez, E. y Tierno, J. (2014). Hiṣn Turī̌s - Castell de Turís - El Castellet. 500 años de historia. Valencia: Universitat de València.

King, D. A. (2018). La alquibla en la Córdoba medieval y la orientación de la Gran Mezquita. Awraq, 17, 187-227.

Kirchner, H. (1999). Una mezquita en Sa Nitja (Menorca). P. Bueno y R. de Balbín (Coords.). II Congreso de Arqueología Peninsular (t. IV, pp. 691-693). Madrid: Fundación Rei Alfonso Henriques.

Lagardère, V. (1993). Campagnes et paysans d'al-Andalus $V I I I^{e}-X V^{e}$ siècles. Paris: Maisonneuve et Larose.

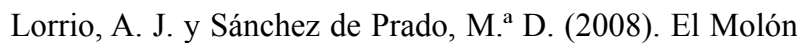
(Camporrobles, Valencia). Un poblado de primera época islámica. Lucentum, XXVII, 141-164. DOI: https://doi. org/10.14198/LVCENTVM2008.27.12

Martín Civantos, J. M., Román, J., Corselli, R., Rouco, J., Romero, P., Delgado, L. y Bonet, M. T. (2019). Memoria final IV Campaña de Excavación en el Pago del Jarafi (Lanteira, Granada). Granada: Delegación Provincial de Granada, Consejería de Cultura, Junta de Andalucía.

Martín Civantos, J. M., Román, J., Rouco, J., Corselli, R., Romero, P., Abellán, J.,... y Moreno, J. M. (2021). Primeros resultados de las excavaciones arqueológicas en el cerro de Mojácar la Vieja (Mojácar, Almería). Un yacimiento islámico fortificado de los siglos XII-XIII. En M. Retuerce (Ed.). Actas del VI Congreso de Arqueología Medieval (EspañaPortugal) (pp. 461-467). Alicante: Asociación Española de Arqueología Medieval.

Navarro, J. y Jiménez, P. (2011). Materiales y técnicas constructivas en la Murcia andalusí (siglos X-XIII). Arqueología de la Arquitectura, 8, 85-120. DOI: https://doi.org/10.3989/ arqarqt.2011.10012 
Negre, J. (2020). En els confins d'al-Andalus. Territori $i$ poblament durant la formació d'una societat islàmica a les Terres de l'Ebre i el Maestrat. Benicarló: Onada Edicions.

Negre, J. y Suñé, J. (2019). Territorio, fiscalidad y actividad militar en la formación de un espacio fronterizo. La consolidación de Tortosa como límite extremo del al-Andalus omeya. Anuario de Estudios Medievales, 49(2), 705-740. DOI: https://doi.org/10.3989/aem.2019.49.2.12

Negre, J., Pérez-Polo, M., Falomir, F., Aguilella, G., Medina, P. y Blasco, M. (2020a). Una lectura contextual del recinto emiral del Tossal de la Vila (Castelló). Algunas reflexiones sobre el origen, morfología y funciones de los asentamientos en altura en el extremo septentrional del Šarq al-Andalus. En C. Doménech y S. Gutiérrez (Eds.). El sitio de las cosas. La Alta Edad Media en contexto (pp. 195-217). Alacant: Publicacions Universitat d'Alacant.

Negre, J., Falomir, F., Pérez-Polo, M. y Aguilella, G. (2020b). Poliorcética, morfología edilicia y técnicas constructivas en el Tossal de la Vila, un recinto fortificado de época emiral en el extremo septentrional del Šarq al-Andalus. En J. Navarro Palazón y L. J. García-Pulido (Eds.). Defensive Architecture of the Mediterranean (pp. 155-162). Granada - València:
Universidad de Granada - Universitat Politècnica de València. DOI: https://doi.org/10.4995/FORTMED2020.2020.11383

Pujante, A. (2002). El Castillo de Puentes y las alquerías de su entorno. Aproximación a la estructura del poblamiento. Alberca, 1, 57-84.

Rius, M. (2000). La alquibla en al-Andalus y al-Magrib al-Aqșà. Barcelona: Institut Millàs Vallicrosa d'Història de la Ciència Àrab.

Rouco, J. (2021). Las fortalezas medievales de la Alpujarra Alta desde la Arqueología de la Arquitectura y del Paisaje. (Tesis doctoral). Granada: Universidad de Granada. Recuperado de: http://hdl.handle.net/10481/71115

Torró, J. (1995). El urbanismo mudéjar como forma de resistencia. Alquerías y morerías en el Reino de Valencia (siglos XIII-XVI). En VI Simposio Internacional de Mudejarismo (pp. 535-598). Teruel: Instituto de Estudios Turolenses.

Walmsley, A. y Damgaard, K. (2005). The Umayyad congregational mosque of Jarash in Jordan and its relationship to early mosques. Antiquity, 79, 362-378. DOI: https://doi. org/10.1017/S0003598X00114152 
